\title{
New strategies and implications for the photoalignment of liquid crystalline polymers
}

\author{
Takahiro Seki
}

The photoalignment of liquid crystalline materials has been studied extensively over the past two and a half decades and has recently become of technological importance in the liquid crystal display panel industry. This review introduces recent attempts at the photoalignment of liquid crystalline polymers and focuses on two aspects. First, strategies to ensure effective in-plane alignment of photoresponsive mesogens are highlighted. Despite the numerous investigations reported to date, film systems have not been well optimized in terms of realizing efficient photoreactions that consider the mesogen orientations. Second, new photoalignable systems composed of block copolymers with surface-grafted polymers and block copolymer films are introduced. The photoalignment processes in these mesoscopic systems involve strong cooperative motion of the different hierarchical size features. In the course of these approaches, a new strategic platform, photoalignment of liquid crystalline polymers via commanding from the free surface, is proposed. These approaches are expected to offer new concepts and possibilities for smart light-responsive materials and systems.

Polymer Journal (2014) 46, 751-768; doi:10.1038/pj.2014.68; published online 13 August 2014

\section{INTRODUCTION}

Photoreactions in ordered media have been the subject of numerous studies. In liquid crystal (LC) systems, molecules are packed with substantial motional freedom, and photoreactions trigger changes in the packing state or the collective molecular orientation. The effects can be amplified to the mesoscopic, microscopic and even macroscopic levels due to strong motional cooperativity. Photochromic reactions have frequently been incorporated in LC media because of their repeatability for controlling material properties. This approach has provided various types of smart, light-responsive materials ${ }^{1}$ exhibiting surface-mediated photoalignment of LC materials, ${ }^{2-6}$ photoinduced phase transitions, ${ }^{7-12}$ photoorientation/addressing of polymer thin films, ${ }^{13-18}$ photoinduced mass migrations, ${ }^{19-28}$ phototactic sliding motions, ${ }^{29-31}$ photo-driven motions and morphology of monolayers, ${ }^{32-35}$ and macroscopic photomechanical deformations. ${ }^{36-46}$

Photoalignment research and technology started in 1988 with the discovery of the reversible alignment control of nematic LCs by the photoisomerization of azobenzene on a substrate surface (Figure 1) by Ichimura et al. ${ }^{47}$ It was demonstrated that the $E / Z$ (trans/cis) photoisomerization of an azobenzene monolayer on a substrate can switch the alignment of nematic LC molecules between the homeotropic and planar modes. This active functional surface was dubbed a 'command surface' or 'command layer.' Shortly after this finding, Gibbons et al., ${ }^{48}$ Dyadyusha et al. ${ }^{49}$ and Schadt et al. ${ }^{50}$ showed that angular selective excitation of an azo dye-doped polyimide or a photocrosslinkable polymer film with linearly polarized light (LPL) led to in-plane alignment control (Figure 2). At the same time, Kawanishi et al. ${ }^{51}$ also reported this effect using an azobenzene self-assembled monolayer. Approaches based on the Langmuir-Blodgett technique have provided a precise understanding of the effects of the molecular design and packing density on the command layer. ${ }^{52,53}$ Successive explorations have revealed that the command layer can control orientations for a variety of materials, including discotic LCs, ${ }^{54,55}$ lyotropic chromonic LCs, ${ }^{56-58}$ LC polymers, ${ }^{59,60}$ semiconducting molecules ${ }^{61,62}$ and mesostructured organic-inorganic hybrids. ${ }^{63-68}$

Photoalignment methods have recently become of practical importance in industry. The surface photoalignment of nematic LCs on polymer films has recently been adopted in processes for LC display panel production. ${ }^{69}$ Non-contact and high-resolution photoalignment processes have considerable advantages when compared with the conventional rubbing processes. ${ }^{4,6}$ Furthermore, many prototypes of photonic LC elements and devices have been fabricated. ${ }^{70}$

This review focuses on recent topics in the photoalignment of azobenzene-containing LC polymer systems. The precise threedimensional (out-of-plane (zenithal) and in-plane (azimuthal)) alignment control of LC materials is of great importance in applications for LC display panels as well as photonic and memory devices. In particular, achieving efficient azimuthal control is a key issue in photoalignment technology. Despite the number of investigations that have been performed, the film design of the alignment layer has not been fully considered in terms of molecular orientation. For effective light absorption by a photoresponsive film, the transition moment of 

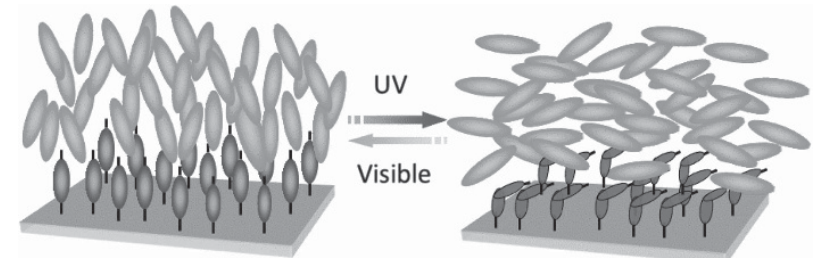<smiles>CC(C)OCONc1ccccc1</smiles>

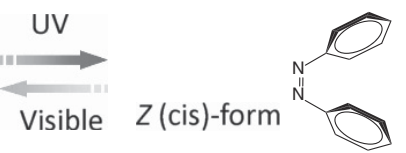

Figure 1 Schematic illustration of reversible photoalignment by a "command surface' composed of an azobenzene monolayer. A full color version of this figure is available at Polymer Journal online.

Linearly polarized light

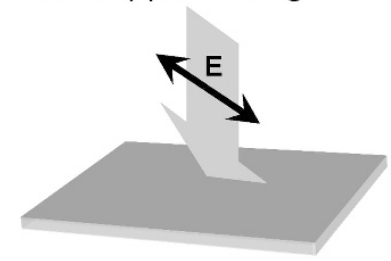

Linearly polarized light
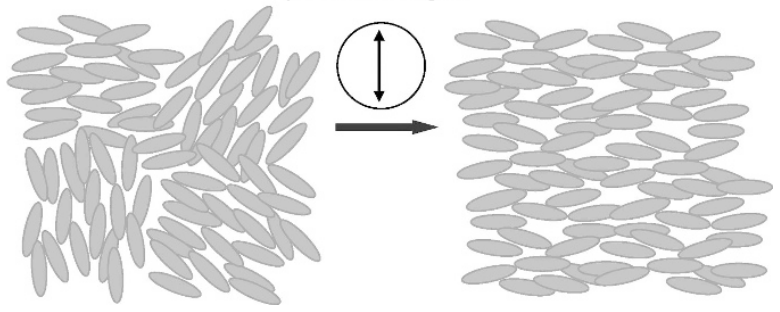

Figure 2 Schematic drawings of irradiation with linearly polarized light (LPL) and oblique non-polarized light (upper). The lower drawing shows a model of aligned monodomain formation in liquid crystals (LCs) by irradiation with LPL. The molecular orientation generally becomes orthogonal to the electric vector $(E)$ of LPL. A full color version of this figure is available at Polymer Journal online.

an azobenzene mesogen should be oriented parallel to the electric vector of the light $(E)$, namely, perpendicular to light propagation (Figure 3). However, in films prepared by ordinary methods, such as spincasting, dip-coating, Langmuir-Blodgett and layer-by-layer assembly, the mesogens are generally oriented vertically to the substrate (Figure 3a). According to theoretical considerations ${ }^{71,72}$ and experimental data, ${ }^{73,74}$ rod-like calamitic mesogens have a tendency to orient perpendicular to the free (air contacting) surface of the film. Many side chain polymers exhibit this tendency. As light irradiation is usually performed with normal incidence to the film (substrate) plane, this orientation results in poor light absorption. To realize planar mesogen orientations for efficient light absorption, some specific strategies must be adopted (Figure $3 \mathrm{~b}$ ). The main objective of this article is to overview the molecular designs and strategies for obtaining planar mesogen orientations. a

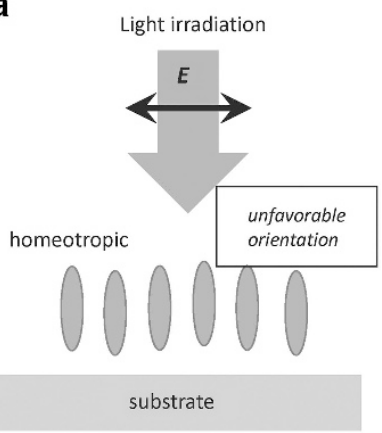

Spin-casting, dip-coating, LB, LbL films of ordinary side chain LC polymers

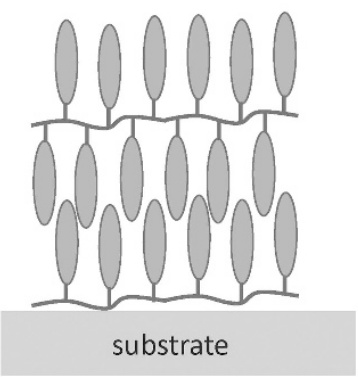

b
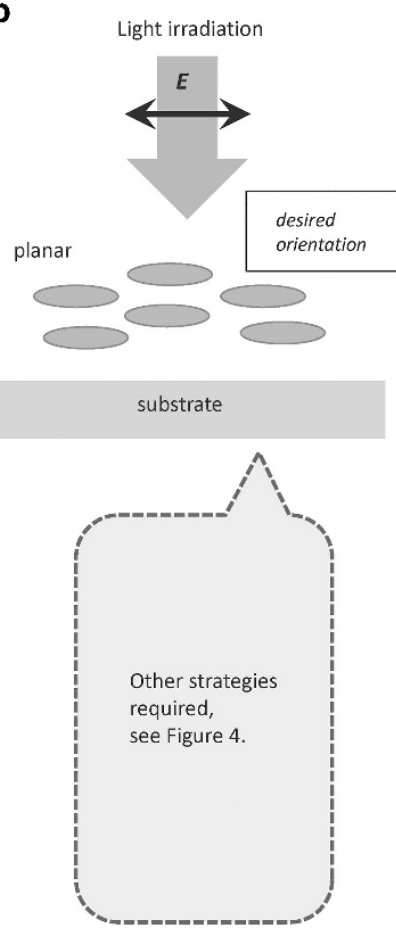

Figure 3 Photoresponsive mesogens in a thin film state. Ordinary calamitic (rod-like mesogenic) side-chain polymer films primarily adopt a homeotropic orientation (a), which is unfavorable for electronic excitation by normally incident light. Other strategies are needed to achieve planar orientations of mesogens (b). A full color version of this figure is available at Polymer Journal online.

In Figure 4, the strategies for realizing the planar orientation of mesogenic groups are schematically summarized. The strategies involve (a) the introduction of mesogens with side-on architecture to the backbone, (b) the introduction of mesogens in the main chain, (c) the synthesis of (head-on) side chain LC polymers directly attached to the surface or (d) by way of a spacer chain of amorphous polymer, (e) the induction of a planar orientation of mesogens with the aid of the confinement effect in a block copolymer and (f) the modification of the free surface of the side chain LC film (f).

Another aim of this article is to emphasize new trends in photocontrols for structures at conventional molecular levels to those of mesoscopic feature sizes (typically range: $10-100 \mathrm{~nm}$ ). Recent ideas have initiated new research areas related to the photoalignment of mesoscopic structures formed in surface brush systems and block copolymer films. The significance of investigating regions of mesoscopic sizes can be found in biological systems. The structure, assembly behavior and function at mesoscopic size ranges could be essential to understanding the boundary between non-living molecules/macromolecules, such as lipids, proteins, DNA and so on, and actual living organizations at the microscopic and macroscopic levels. Considering this point, the development of methods for controlling materials at the mesoscopic level should be meaningful and alluring because of the material chemistry. Mesoscopic systems are expected to bridge the photoresponsive phenomena of different size ranges between molecular ${ }^{75-77}$ and macroscopic functions ${ }^{36-46}$ and provide panoscopic views of photoresponsive smart materials. 
a

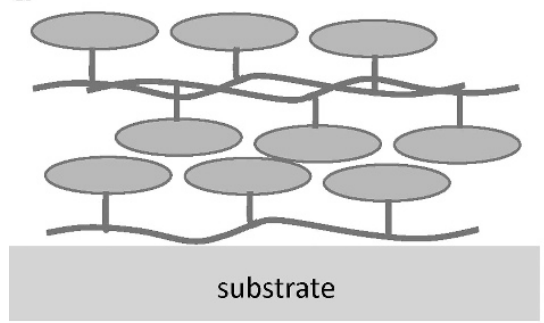

c

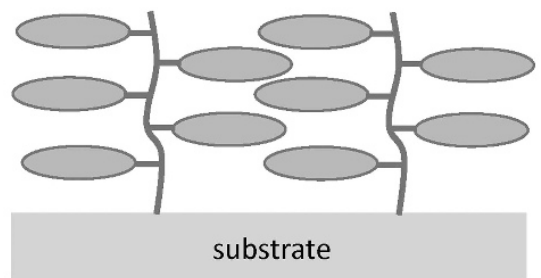

e

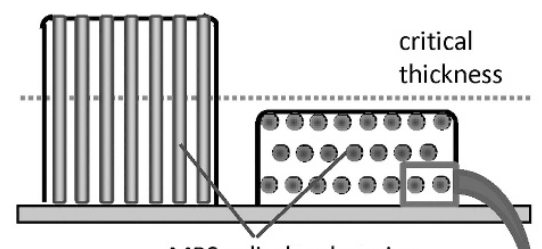

MPS cylinder domains

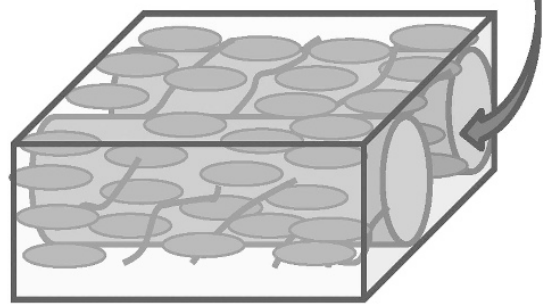

b

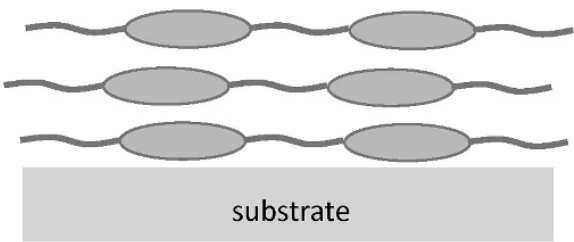

d

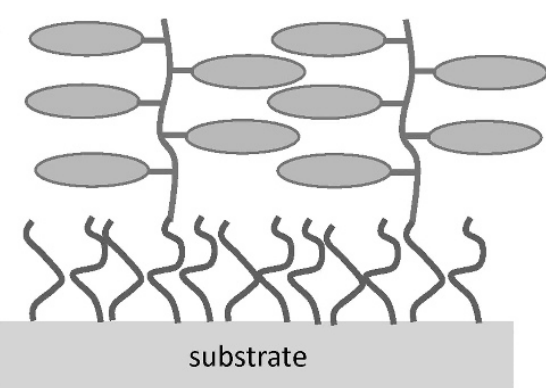

f skin layer at free surface

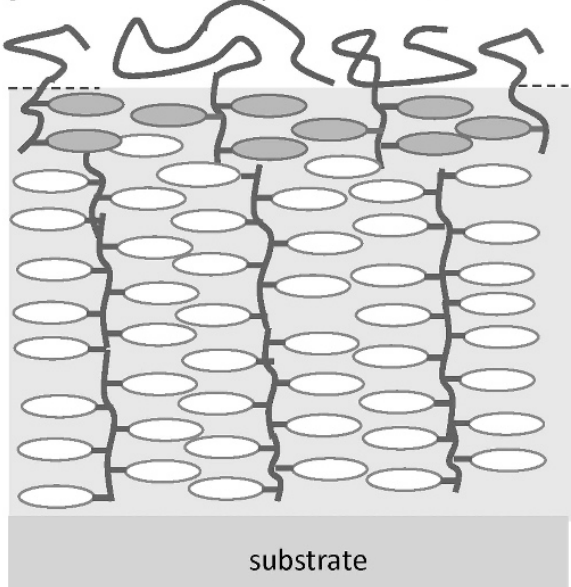

Figure 4 Schematic diagrams for the strategy to attain the in-plane orientation of photoresponsive (mostly azobenzene) mesogens. (a) Spincast films of liquid crystal (LC) polymers with side-on type mesogens. (b) Spincast films of main chain LC polymers. (c) Side chain LC polymers grafted onto the substrate surface. (d) Side chain LC polymers of block copolymer grafted onto the substrate surface via an amorphous spacer layer. (e) Planar orientation of mesogens by block copolymers constrained to an ultrathin film. (f) Induction of planar orientation by the modification of a free surface layer. A full color version of this figure is available at Polymer Journal online.

\section{SIDE-ON ATTACHMENT OF MESOGENS TO THE POLYMER BACKBONE}

Rod-like azobenzene units are generally connected to the polymer backbone with a spacer, introduced at the para-position (head-on) of the azo group. In the command surface systems for in-plane control of nematic LCs, this head-on type polymer architecture has some drawbacks. First, the mesogens are pre-oriented homeotropically in the thin film state. Thus, large photon doses are required to induce in-plane anisotropy. Second, the alignment induced by LPL is not retained persistently. The alignment gradually changes to a homeotropic state after a long period via thermal conversion of azobenzene to the trans form. To overcome these issues, Ichimura et al. ${ }^{78-80}$ designed polymers with azobenzene mesogens connected at the ortho-position of the azo group (side-on) so that the azobenzene mesogen is directed parallel to the substrate ${ }^{78}$ or polymer backbone (Figure 5, case a in Figure 4). ${ }^{79,80}$ With this side-on type architecture, the efficiency for inducing the in-plane orientation was drastically increased; the light dose was reduced from a few $\mathrm{Jcm}^{-2}$ to $50-100 \mathrm{~mJ} \mathrm{~cm}^{-2}$. In addition, the induced azimuthal optical anisotropy became persistent, irrespective of the isomeric form of azobenzene. ${ }^{79}$

Li et al. ${ }^{81}$ were the first to systematically investigate the LC properties and photoinduced phase transition of polymers with side-on architecture. Unlike ordinary end-on type LC polymers, the polymer only adopted a nematic phase, and no smectic phase was observed. Xie, Zhang et al. ${ }^{82}$ reported on ladder-like polysiloxane films containing a dual photoreactive cinnamate/azobenzene unit with the side-on architecture. The longer spacer connecting the dual photoresponsive units provided better alignment properties because more favorable cooperative molecular motions were allowed. Petr and Hammond ${ }^{83}$ reported that a side-on azobenzene polymer with a flexible siloxane backbone showed a rapid photoinduced phase transition from a nematic to isotropic phase at room temperature. This facile phase transition was ascribed to the high photoreactivity in 

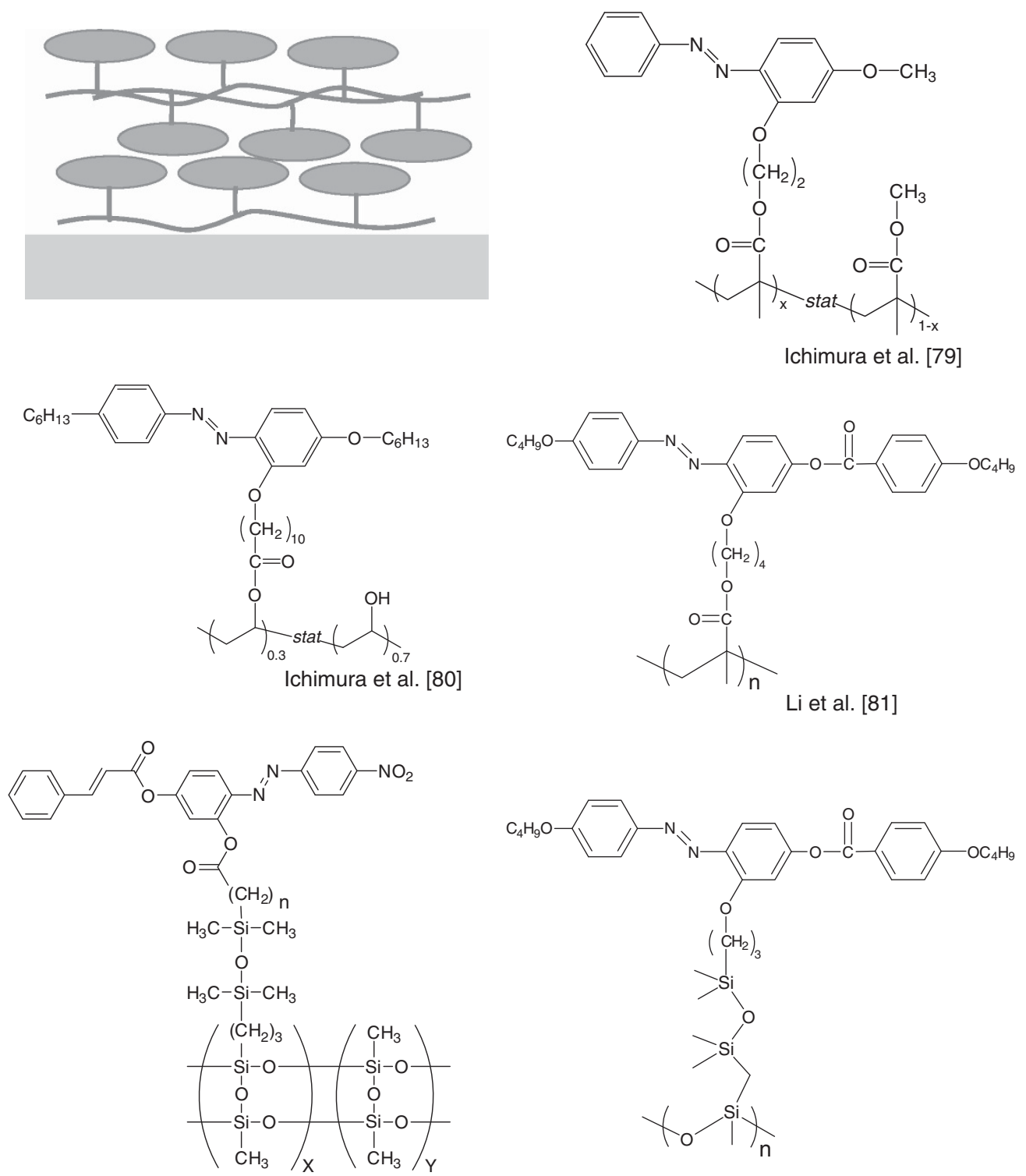

Xie, Zhang et al. [82]

Petr \& Hammond [83]

Figure 5 Side-on mesogen type photoresponsive polymers for in-plane photoalignment (case a in Figure 4). A full color version of this figure is available at Polymer Journal online.
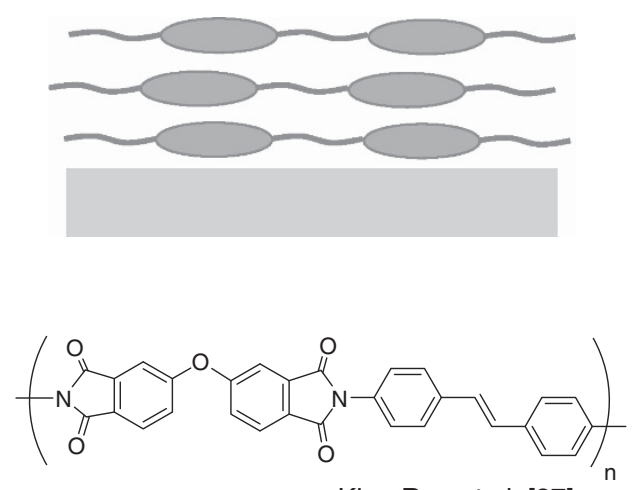

Kim, Ree et al. [87]<smiles>CC(C)c1ccc(N=Nc2ccc(-n3c(=O)c4cc5c(=O)n(C(C)(C)C)c(=O)c5cc4c3=O)cc2)cc1</smiles>

Sakamoto et al. [61,84,85]<smiles>COC(=O)/C=C/c1ccc(/C=C/C(=O)OC(C)(C)C)cc1</smiles>

Song et al. [88]

Figure 6 Main chain mesogen type photoresponsive polymers for in-plane photoalignment (case b in Figure 4). A full color version of this figure is available at Polymer Journal online. 
a relatively disordered environment compared with end-on type azobenzene LC polymers. The chemical structures of these polymers are summarized in Figure 5.

\section{PHOTORESPONSIVE MAIN CHAIN LC POLYMERS}

Most studies have used side chain type LC polymers. However, main chain LC-type polymers (case b in Figure 4) also serve as fascinating photoalignment layers. Azobenzene, ${ }^{84-86}$ stilbene, ${ }^{87}$ cinnamate-type ${ }^{88-90}$ and chalcone $e^{91,92}$ functionalities have been introduced into polyester and polyimide main chain structures. In Figure 6, a few examples from these series are displayed. These polymer films are well suited for in-plane anisotropy. Interestingly, in the polyester films reported by Song et al. ${ }^{88}$ the alignment ability was dependent on the even/odd number of the methylene spacer. Photoalignment control was more effectively achieved for the polymers with an even number of spacers.

a
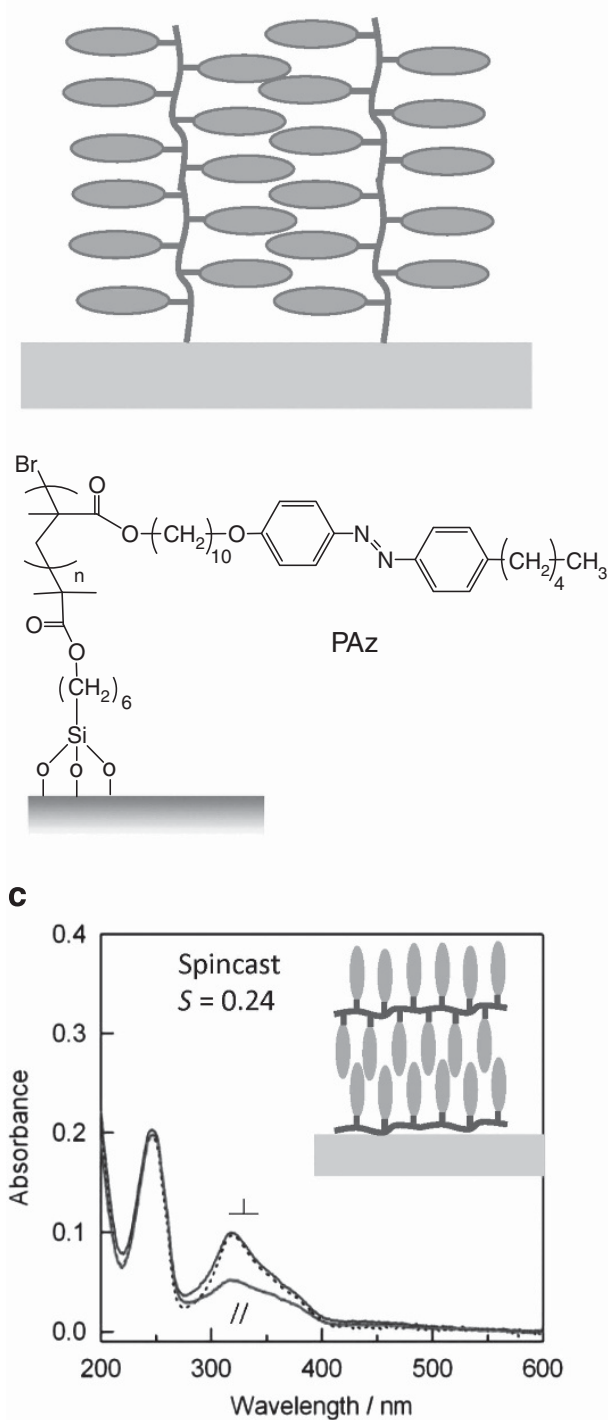

As expected, main chain LC polymers have superior stability and durability against heat and extreme environmental conditions. As a result of this high stability, the pretilt angles are favorably fixed by oblique irradiation. ${ }^{85}$ They can be used for typical nematic LCs as well as organic semiconductor oligomers and polymers ${ }^{61}$ that require particular alignment conditions. However, such robustness can be a drawback for their alignment processability. Large amounts of light exposure, typically reaching tens of $\mathrm{J} \mathrm{cm}^{-2}$, are required to induce anisotropy because of the restricted motion of the photoresponsive unit. The balance between robustness and light sensitivity has to be considered for the actual applications.

\section{SURFACE-GRAFTED LC AZOBENZENE POLYMER CHAINS}

Side chain non-photoresponsive LC polymers have been studied previously. ${ }^{93-95}$ However, precise information on the side chain orientation has not been well elucidated. Uekusa et al. ${ }^{96}$ were the

\section{b}
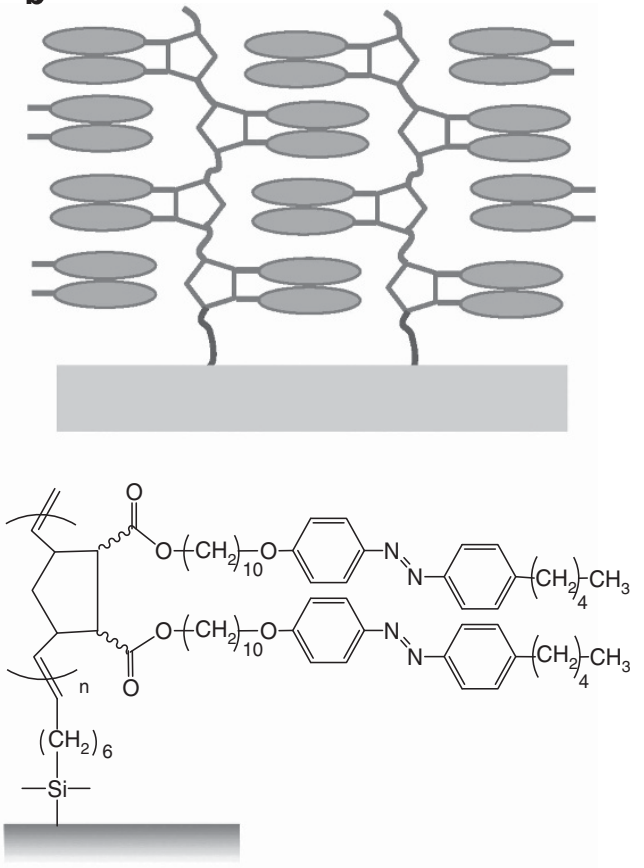

d

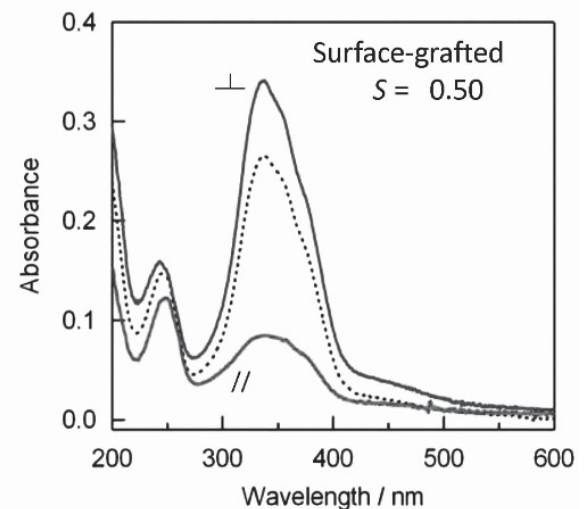

Figure 7 Surface-grafted side chain liquid crystal (LC) azobenzene polymers for in-plane photoalignment (case c in Figure 4). Side chain polymers are synthesized by surface-initiated atom transfer radical polymerization (SI-ATRP; PAz) (a) and surface-initiated ring opening metathesis polymerization (SI-ROMP) (b). The polarized ultraviolet-visible absorption spectra of Paz after photoalignment by linearly polarized light (LPL) irradiation for a spincast film (c) and a surfacegrafted film synthesized by SI-ATRP (d). The dotted lines correspond to the spectra before LPL irradiation. In each spectrum, the orientation order parameter (S) is indicated. Adapted with permission. ${ }^{98}$ Copyright 2009, American Chemical Society. A full color version of this figure is available at Polymer Journal online. 
first to synthesize a surface tethered azobenzene LC side chain polymer (PAz) by surface-initiated atom transfer radical polymerization (ATRP) (scheme in Figure $7 \mathrm{a}$, case $\mathrm{c}$ in Figure 4) following the method reported by Fukuda and Tsujii. ${ }^{97}$ In surface tethered films with sufficiently high two-dimensional density, the azobenzene mesogens were preferentially oriented parallel to the substrate. ${ }^{19,96}$ This unique orientation was confirmed by ultravioletvisible absorption spectroscopy and grazing angle incidence X-ray diffraction measurements. Similar to the cases of side-on polymer films, surface-grafted LC azobenzene chains are beneficial for efficient light absorption and in-plane photoalignment. Highly ordered inplane orientation is readily attained in this architecture. ${ }^{98}$ The degree of in-plane alignment for grafted PAz films has been evaluated by the optical order parameter $\left(S=\left(A_{\perp}-A_{\|}\right) /\left(A_{\perp}+2 A_{\|}\right)\right.$, where $A_{\perp}$ and $A_{\|}$ are the absorbances observed with a probing beam in the perpendicular and parallel directions for the peak of the $\pi \pi^{*}$ band, approximately $350 \mathrm{~nm}$; see spectra in Figures $7 \mathrm{c}$ and d. In a spincast film, irradiation with LPL up to $2 \mathrm{~J} \mathrm{~cm}^{-2}$ resulted in only $S=0.24$ (Figure 7c). In contrast, for a surface-grafted polymer, a strong order parameter of $S=0.50$ was readily obtained by irradiation with $400 \mathrm{~mJ} \mathrm{~cm}^{-2}$ (Figure 7d). The molecular orientation can be switched to the other direction by irradiation with the corresponding LPL. However, when the two-dimensional density of the chain is not high, homeotropic mesogen orientation is observed, similar to spincast films.

Surface-grafted azobenzene LC chains can be utilized as a command surface for nematic LCs. Camorani et al. ${ }^{99}$ prepared a similar surface-grafted LC azobenzene polymer and evaluated the
PAz

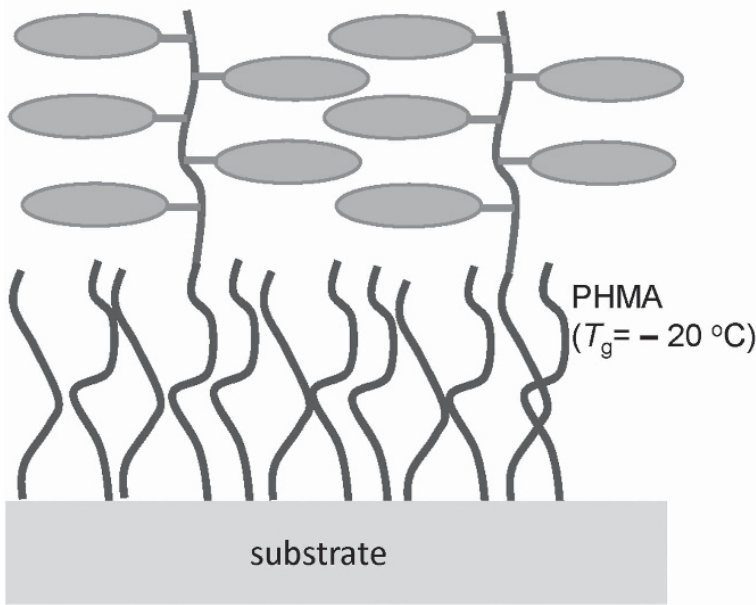

1st-ATRP

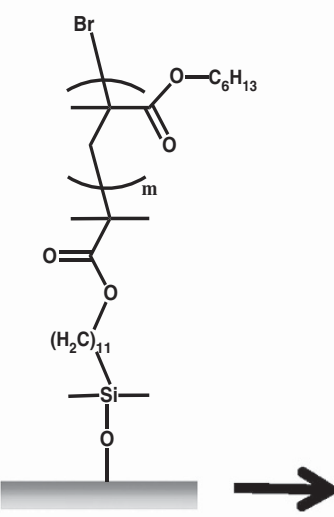

PHMA

\section{2nd-ATRP}

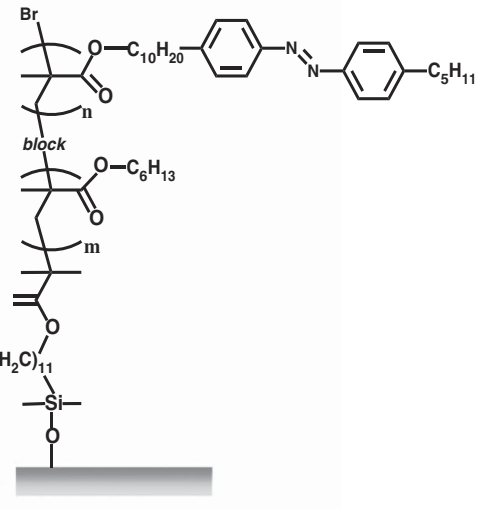

PHMA-b-PAzMA

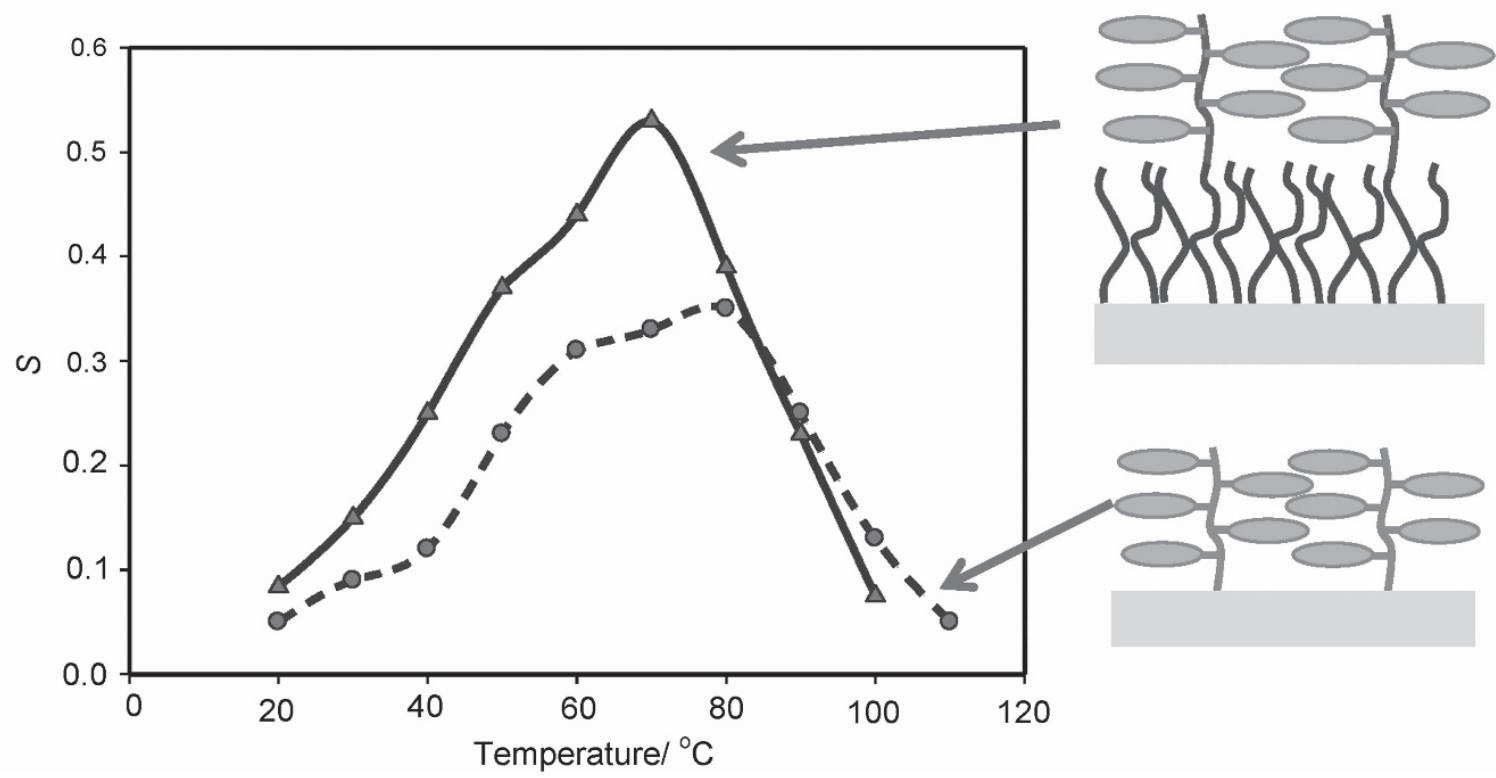

Figure 8 Surface-grafted side-chain azobenzene liquid crystal (LC) polymers with a diblock architecture, synthesized by surface-initiated atom transfer radical polymerization (SI-ATRP) for in-plane photoalignment (case $d$ in Figure 4). A flexible chain of poly(hexyl methacrylate) (PHMA) is introduced between PAz and the substrate. The figure below indicates the in-plane orientation order parameter $(S)$ achieved by linearly polarized light (LPL) irradiation as a function of temperature during the irradiation procedure. The dashed and solid lines correspond to the data for films with and without the flexible chain, respectively. Adapted with permission. ${ }^{101}$ Copyright 2012. American Chemical Society. A full color version of this figure is available at Polymer Journal online. 
photoalignment behavior of this surface. Excellent in-plane control in a twisted nematic LC was demonstrated for a cell prepared by the rubbing method.

Surface-initiated ring opening metathesis polymerization of a norbornene monomer using Grubbs catalyst (third generation) can be an alternative procedure for synthesizing surface-grafted LC polymer chains (scheme in Figure $7 \mathrm{~b}$ ). ${ }^{100}$ In this procedure, controlled grafted chains are readily available because the polymerization is tolerant of oxygen during the polymerization. Surface-grafted chains with more closely packed mesogens are obtained when a cyclic olefin monomer with two azobenzene substituents is used (see chemical structure in Figure $7 \mathrm{~b}$ ). The mesogens are azimuthally packed to a higher degree so that reorientation by irradiation with another LPL is partially suppressed.

Hafiz et al. ${ }^{101}$ conducted a two-step atom transfer radical polymerization to introduce flexible amorphous polymer chains beneath the LC azobenzene polymer (case d in Figure 4). An amorphous brush of poly(hexyl methacrylate) (PHMA, glass transition temperature $=-20^{\circ} \mathrm{C}$ ) was first synthesized, and the azobenzene side chain polymer $(\mathrm{PAz})$ was subsequently overlaid by ATRP (scheme in Figure 8).

The graph in Figure 8 shows the $S$ values obtained after irradiation with $436 \mathrm{~nm} \mathrm{LPL}$ at $500 \mathrm{~mJ} \mathrm{~cm}^{-2}$. As shown, the magnitude of inplane photoalignment by LPL was a function of temperature. The photoalignment was performed favorably at temperatures where $\mathrm{PAz}$ adopted an SmA phase, and the optimum condition was $\sim 30-40{ }^{\circ} \mathrm{C}$ below the isotropization temperature $\left(116^{\circ} \mathrm{C}\right)$. The $S$ value of photoaligned PAz (thickness, ca $8 \mathrm{~nm}$ ) reached a higher level for the brush with a flexible PHMA chain compared with the PAz brush of a comparable thickness but without a flexible chain. Thus, the introduction of a flexible spacer facilitates efficient in-plane photoinduced rotation. In addition, the reorienting motion after irradiation with LPL of different directions readily occurred. The underlying PHMA chain works as a lubricant buffer layer in the double-layered grafting architecture. In this way, the flexible chains have an important role in decoupling the molecular motion of PAz mesogens from the solid substrate. In the design of side chain LC polymers, the incorporation of a flexible spacer between a mesogenic group and the polymer backbone is essential. ${ }^{102}$ In the present system, the flexible amorphous chains can be regarded as a 'mesoscopic spacer.' The length of the amorphous chains also influences the photoalignment behavior. A longer amorphous chain lead to a larger value for the order parameter. ${ }^{103}$

The thermophysical properties of spacer chains should also influence the photoalignment behavior of LC PAz layers. In this context, amorphous polymers with different $T_{\mathrm{g}}$ were used as spacer chains (Figure 9). Here, the first step of ATRP was undertaken to prepare three types of poly(alkyl methacrylate) spacers: PHMA $\left(T_{\mathrm{g}}=\right.$ $-20^{\circ} \mathrm{C}$; very flexible), poly(butyl methacrylate) (PBMA, $T_{\mathrm{g}}=27^{\circ} \mathrm{C}$; moderately flexible) and poly(methyl methacrylate) (PMMA,
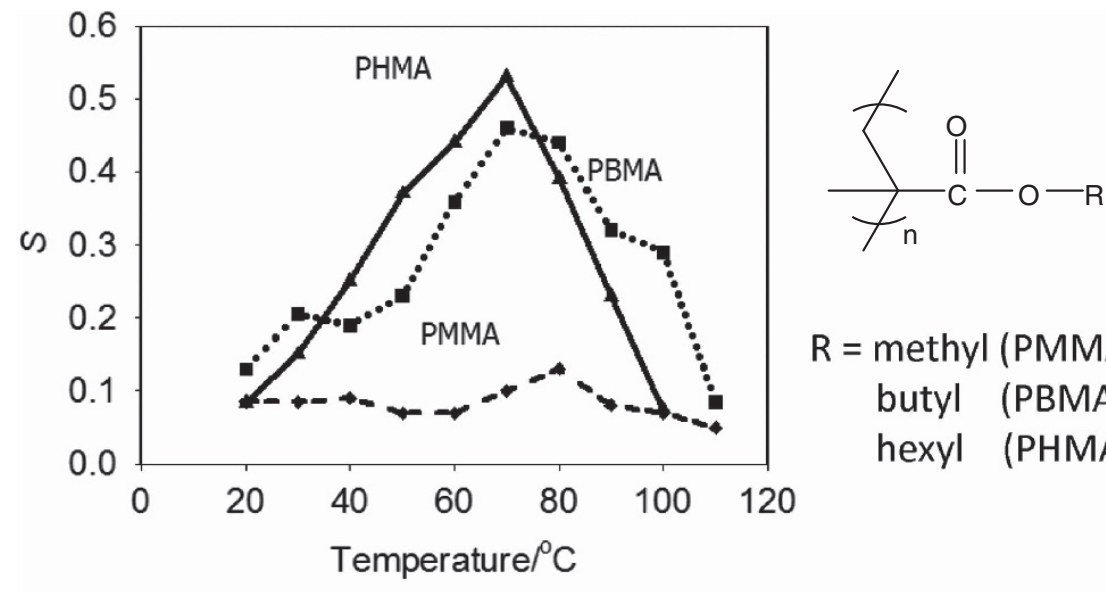

$$
\begin{array}{r}
R=\text { methyl (PMMA) } \\
\text { butyl (PBMA) } \\
\text { hexyl (PHMA) }
\end{array}
$$

$S=0.53$

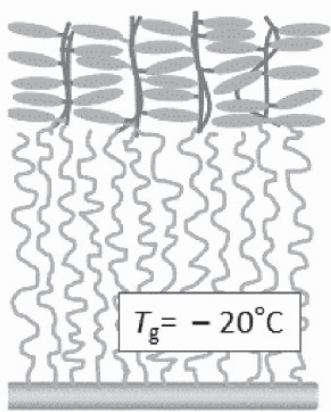

PHMA

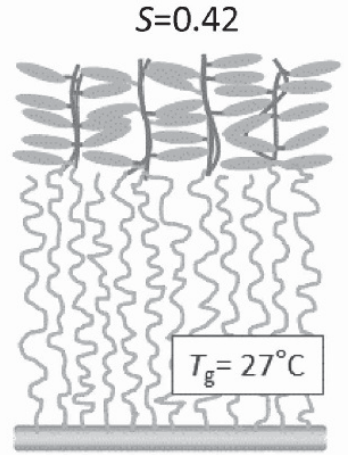

PBMA

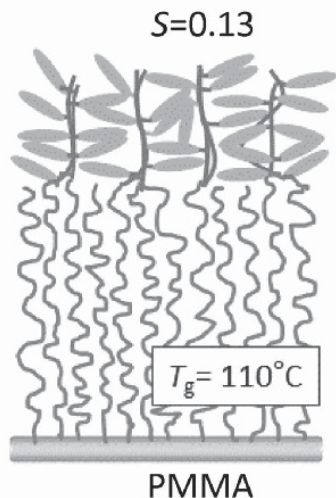

Figure 9 Photoalignment behavior of PAz obtained in the diblock framework with an amorphous alkyl methacrylate chain of different $T_{\mathrm{g}}$. The figure below indicates the in-plane orientation order parameter $(S)$ achieved by linearly polarized light (LPL) irradiation as a function of temperature during the irradiation procedure. Schematic drawings indicating the azobenzene mesogen alignment states are displayed below. Adapted with permission. ${ }^{104}$ Copyright 2013 , American Chemical Society. A full color version of this figure is available at Polymer Journal online. 
$T_{\mathrm{g}}=110^{\circ} \mathrm{C}$; glassy). PAz is then polymerized by ATRP on top of the poly(alkyl methacrylate) layers. The $S$ values at the optimum temperature $\left(70-80^{\circ} \mathrm{C}\right)$ for PHMA, PBMA and PMMA were 0.53, 0.42 and 0.13 , respectively. ${ }^{104}$ Thus, the magnitude of $S$ follows the opposite trend of $T_{\mathrm{g}}$, that is, the more flexible chains provide smoother cooperative motion for the photoinduced in-plane (re)orientation. The photoinduced alignment was particularly suppressed for PMMA. Thus, the segmental mobility in the rubbery or glassy state critically affects the photoinduced motions. The $S$ value for photoaligned $\mathrm{PAz}$ on the PMMA layer at the optimized temperature $\left(80^{\circ} \mathrm{C}\right)$ was unexpectedly small $(S=0.13)$, which is even smaller than that of a PAz homopolymer brush of comparable thickness $(S=0.35)$. It appears that the PAz layer adhered to the PMMA layer more strongly than to the quartz surface.

The photoinduction of in-plane anisotropy can be repeated many times (at least 15 times) at the optimum temperature without deterioration. Once the photoinduced anisotropy is attained, these brushes retained the in-plane anisotropy, even for a month, as long as they were kept at room temperature, below the $T_{\mathrm{g}}$ of the PAz chain $\left(=53^{\circ} \mathrm{C}\right)$.

\section{PHOTOALIGNMENT OF BLOCK COPOLYMER THIN FILMS}

Block copolymers that form phase-separated structures with 10-100$\mathrm{nm}$ size features have attracted considerable attentions from a practical viewpoint for next-generation nano-lithographic applications. ${ }^{105,106}$ To achieve desired alignment in microphase-separated (MPS) structures, a number of efforts have been made based on applying external fields, such as shear, electric and magnetic fields, solvent evaporation flows, and surface alignment, such as mesoscopic topographical and surface wetting patterns. ${ }^{107-109}$

Thermotropic LC polymers incorporated into an MPS structure can offer hierarchical orientational molecular order in different ways than phase-separated structures. Particularly, in the case of side chain LC block polymers, the interfaces between blocks are usually formed parallel to the oriented side-chain mesogens. ${ }^{110}$ Therefore, the orientation of MPS structures in LC block copolymers strongly
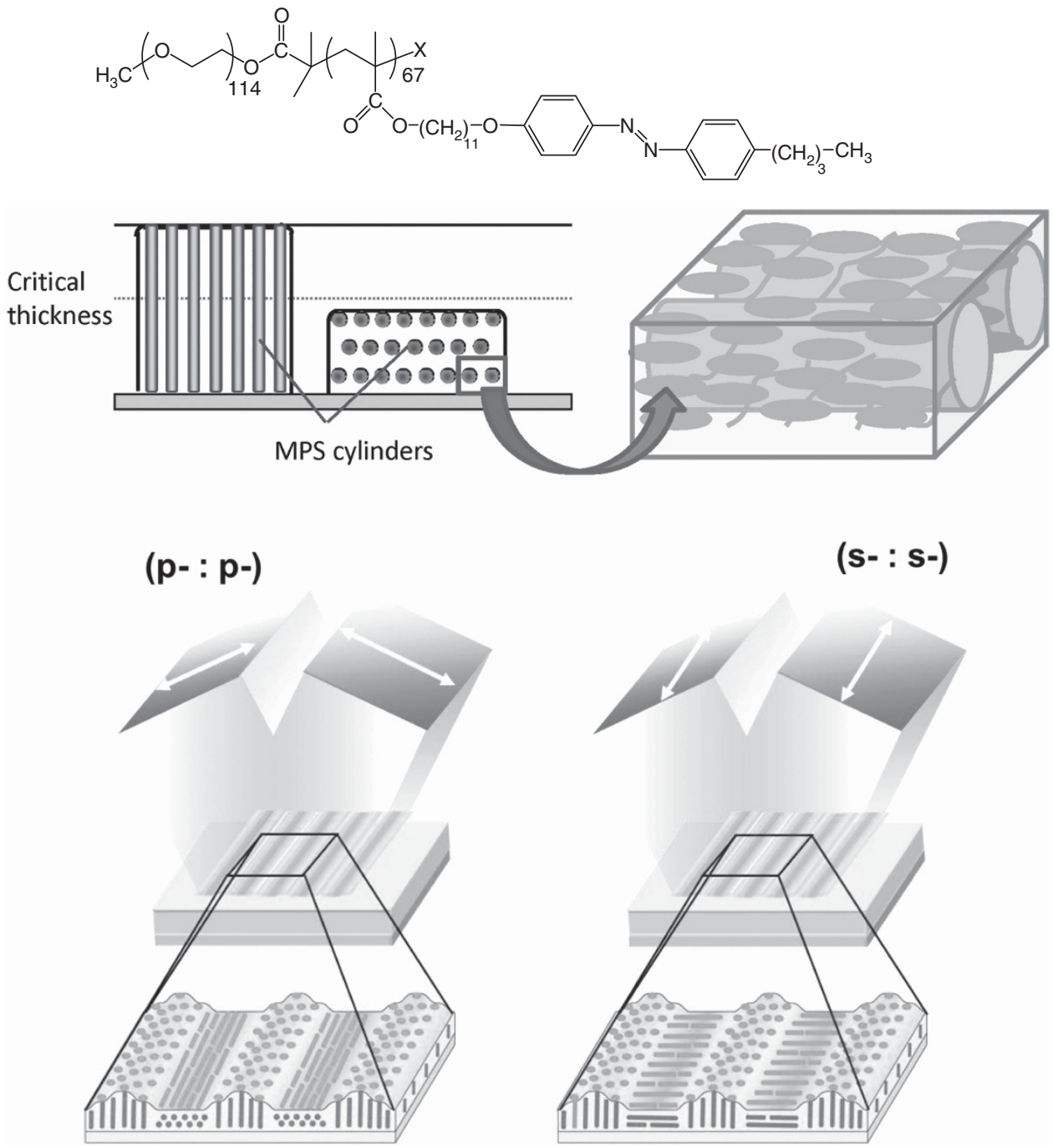

Figure 10 Schematic illustration of the thickness dependent orientation of poly(ethylene oxide)-based azobenzene-containing liquid crystal (LC) polymer films (PEO-PAz) (upper). Below a critical thickness $(<70 \mathrm{~nm})$, this polymer exhibits a planar orientation (case e in Figure 4$)$. Schemes of PEO orientation following surface relief grating (SRG) formation after irradiation with interference argon ion laser beams (lower). The in-plane orientation of PEO cylinders depends on the polarization mode of the laser beam. Adapted with permission. ${ }^{118}$ Copyright 2006 , John Wiley \& Sons. A full color version of this figure is available at Polymer Journal online. 
depend on the nature of the LC block orientation. ${ }^{10,111}$ In thin films, Iyoda et al. ${ }^{112-114}$ demonstrated the formation of highly ordered vertical cylindrical structures with homeotropic orientation for a smectic LC azobenzene polymer matrix of amphiphilic LC block copolymers. Zhao et al. ${ }^{115}$ showed an orientational cooperative effect in an LC azobenzene block connected with a non-photoresponsive LC block.

Attempts to perform the photoalignment of MPS structures in azobenzene LC block copolymer films started in 2006. Yu et al. ${ }^{116,117}$ and Morikawa et al. ${ }^{118,119}$ independently demonstrated the in-plane photoalignment of MPS cylinder morphologies in azobenzenecontaining block copolymer films by irradiation with LPL. In the years since, considerable data have been accumulated, and several reviews on this topic are now available. ${ }^{5,19,120-124}$ The orientations of azobenzene mesogenic groups and MPS cylinder domains have been found to be dependent on the film thickness. For poly(ethylene oxide) (PEO)- $b$-PAz (Figure 10), a critical thickness was determined to be $70 \mathrm{~nm}$. In films of PEO- $b-\mathrm{PAz}$ with larger thickness, a homeotropic (vertical) orientation is adopted, and below this level, the MPS cylinders are oriented parallel to the substrate. ${ }^{118,125}$ This orientational transition seems to originate from the cooperative behavior of this system associated with constraint from the solid substrate. Regardless, with the aid of the confinement, the mesogenic groups are oriented parallel to the substrate among the mesoscaled MPS polymer domains in ultrathin film conditions (Figure 10, upper scheme; case e in Figure 4).

A thin film of PEO- $b$-Paz was subjected to the formation of surface relief grating by exposure to interference beams of argon ion laser. ${ }^{118}$ By adjusting the initial thickness, this procedure results in surface undulations with higher and lower areas above and below the critical thickness $(70 \mathrm{~nm})$. In surface relief grating films, vertically and horizontally oriented MPS cylinders are patterned in the thicker and thinner regions, respectively (Figure 10, lower scheme). More interestingly, the MPS cylinder domains can be aligned parallel and perpendicular to the undulations, depending on the polarization mode of the interference irradiation light. Here, three different hierarchical structures are aligned only by simple irradiation. Namely, these structures consist of alignments of smectic layers (molecular level), MPS cylinder domains (mesoscopic level) and surface undulations (micrometer level).

When an LC azobenzene block is connected with polystyrene (PS) (PS- $b-\mathrm{PAz})$, the MPS of the PS domain can be switched on-demand<smiles>[R12]OS(=O)(=O)OCCOc1ccc(N=Nc2ccc(CC)cc2)cc1</smiles>
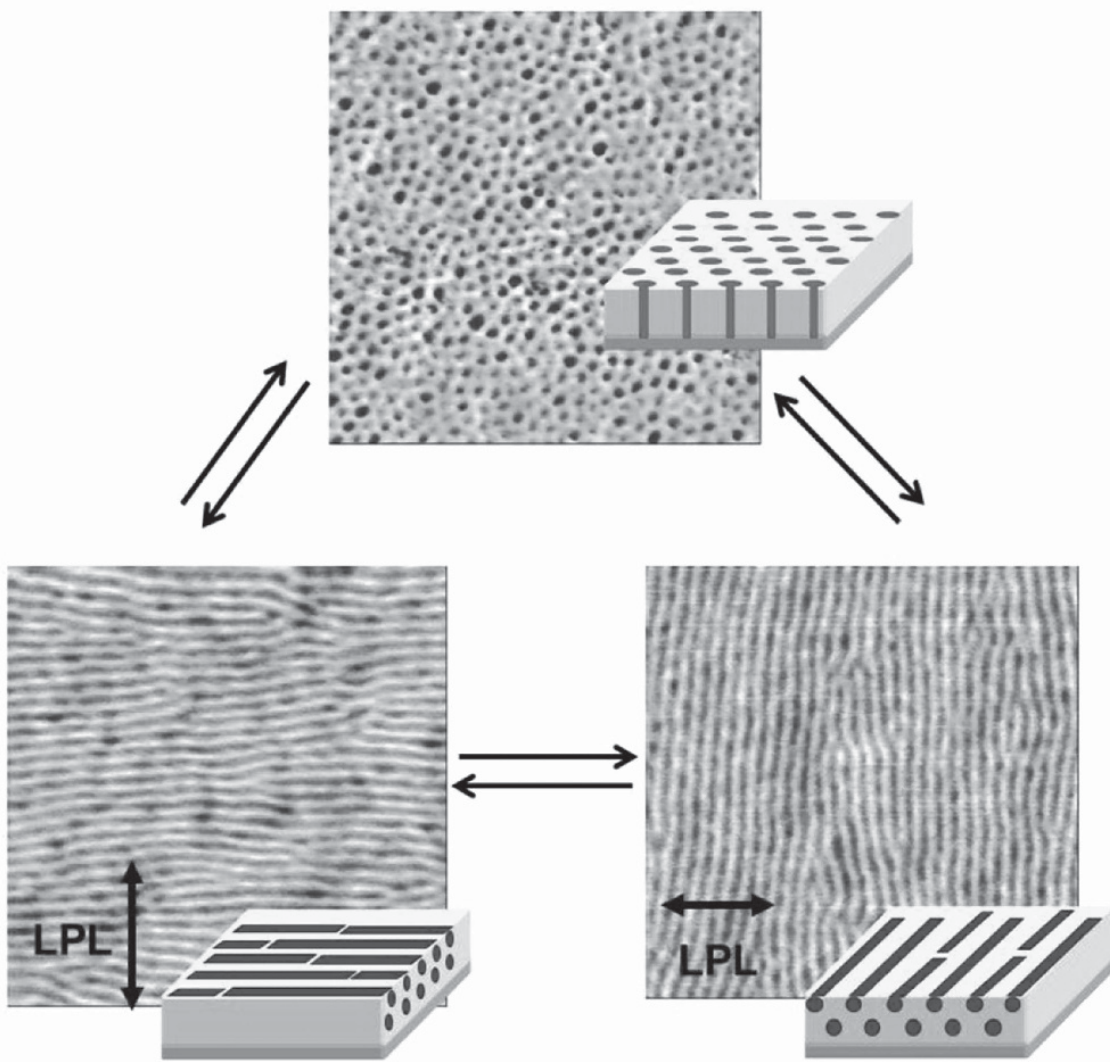

Figure 11 Out-of-plane and in-plane repeatable three-dimensional alignment control of microphase-separated (MPS) cylinder domains in a PS- $b$-PAz film. In each rewriting process, heating and cooling procedures are required. Adapted with permission. ${ }^{119}$ Copyright 2007, American Chemical Society. A full color version of this figure is available at Polymer Journal online. 
between out-of-plane and in-plane directions (Figure 11). ${ }^{119}$ The photoalignment process provides oriented MPS morphologies over a large area in non-contact and addressable manners, without using particular devices. In the first stage, the photoalignment of PS cylinder domains has been attempted at room temperature. At this temperature, the alignment of azobenzene mesogens at molecular scales is changed from the initial vertical state to the in-plane direction, depending on the LPL direction. However, the direction of the MPS domains at the mesoscopic scale remains vertical, irrespective of the azobenzene orientation. Successful on-demand alignment of PS cylinders can be performed when the film is first heated to $130{ }^{\circ} \mathrm{C}$ (above $T_{\mathrm{g}}$ of PS and above the isotropization temperature of PAz) and successively irradiated with LPL while slowly cooling down through a SmA phase temperature region to room temperature, giving a glassy state. By heating to $130^{\circ} \mathrm{C}$, the anisotropic domain formation disappears; therefore, a 'reset (initialization)' of the film is attained. The direction of the PS cylinders can be altered using the same procedure with another LPL irradiation. Horizontally aligned PS cylinders return to the vertical state when irradiated with normally incident non-polarized light. This rewritable system is unique in that one material can encode three types of orthogonal, independent information ( $x, y$ and $z$ directions) (Figure 11). In contrast, in most other cases information switching is performed between two states. As will be mentioned later, PS- $b-\mathrm{PAz}$ is prone to adopt a homeotropic orientation in the annealing process. The three state switching requires careful control of the film thickness and temperature.

\section{TIME COURSE OBSERVATIONS OF MPS PHOTOALIGNMENT IN BLOCK COPOLYMERS}

How the MPS structure changes its orientation is a topic of great interest. To gain detailed insight into the process, Nagano et al. ${ }^{126}$ conducted synchrotron X-ray measurements to simultaneously achieve real-time observations during orientational changes of the mesogens and MPS cylinder morphology at a constant temperature in

a
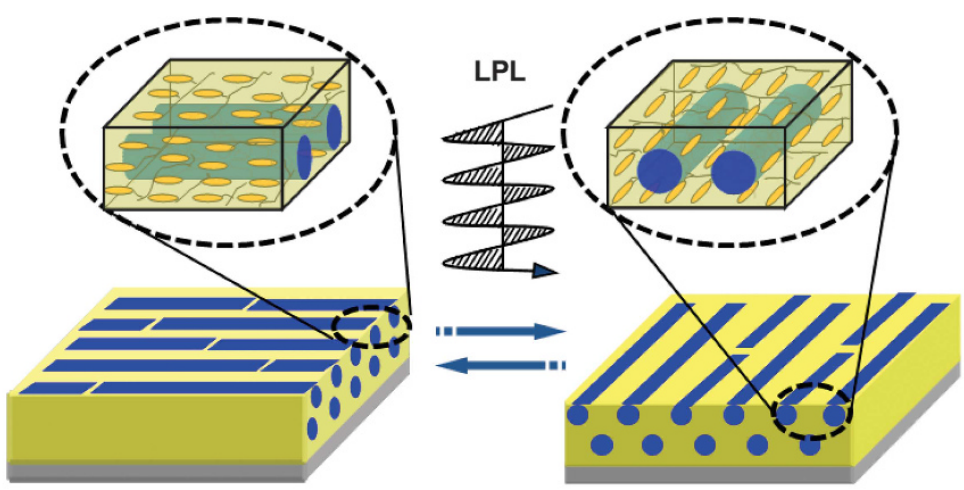

b

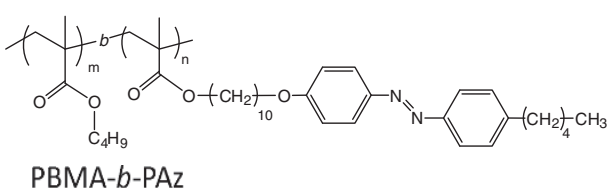

d

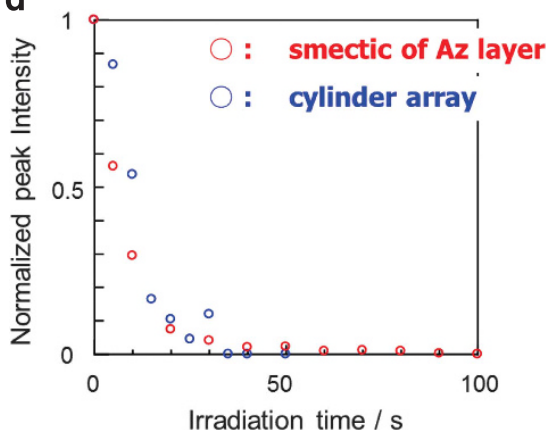

C

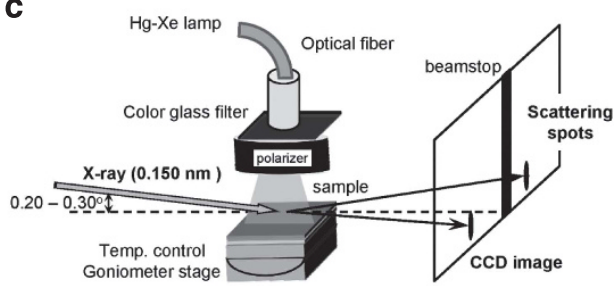

e

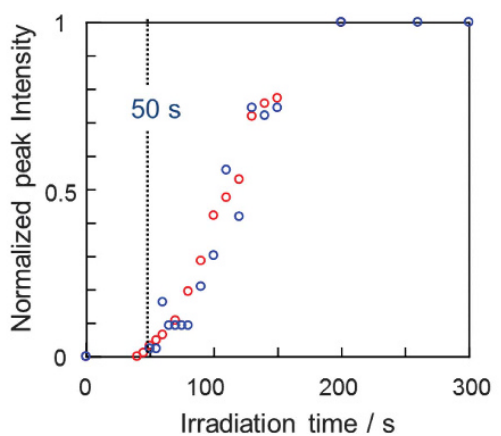

Figure 12 Schematic illustration of direct (isothermal) azimuthal photoswitching of microphase-separated (MPS) cylinder domain alignment in poly(butyl methacrylate) (PBMA)-b-PAz (a) and the chemical structure of this polymer (b). (c) Diagram of the experimental setup for the real-time grazing incidence angle X-ray scattering (GI-SAXS) measurement. (d) Time course profiles of the decaying process scattering peak for the smectic azobenzene layer and a cylinder array of PBMA. The peak intensities are normalized to the maximum signal. (e) Time course profiles of the peak enhancing process for the two peaks. Adapted with permission. ${ }^{126}$ Copyright 2012, John Wiley \& Sons. 
the SmA LC range. A schematic drawing of the photoswitching process is presented in Figure 12a. In this case, the LC azobenzene block copolymer with PBMA, possessing a glass transition temperature around room temperature (PBMA- $b-\mathrm{PAz}$, Figure $12 \mathrm{~b}$ ), is adapted. Interestingly, unlike the previous PS case, this block copolymer always exhibits random planar or homogeneous (uniform planar) orientations of the mesogens and MPS cylinders without forming a homeotropic orientation in films with thicknesses of $100-200 \mathrm{~nm}$ or more. Owing to this in-plane character, alignment switching between the orthogonal directions can be readily monitored at temperatures corresponding to the SmA phase of PAz (typically $95^{\circ} \mathrm{C}$ ). This feature is due to the coverage of the PBMA layer on the topmost surface, which will be discussed in more detail in the following sections.
Figure $12 \mathrm{c}$ shows a schematic experimental setup for the real-time grazing incidence angle X-ray scattering (GI-SAXS) measurements using a synchrotron X-ray source (Photon factory, KEK, Tsukuba, Japan). A sample film was maintained at a target temperature and irradiated with LPL at $436 \mathrm{~nm}$ from the top using an optical fiber and a polarizing prism. The X-ray $(0.150 \mathrm{~nm})$ beam was set at a grazing angle, and the scattered beam was detected with a CCD camera. Figures $12 \mathrm{~d}$ and e show time course profiles of the normalized intensity of the scattered X-ray ascribed to the cylinder distance of the MPS PBMA domains and the smectic layer of azobenzene mesogens, taken at an appropriate azimuthal direction. The PBMA- $b-\mathrm{PAz}$ film was initially photoaligned by LPL, and another LPL irradiation at the azimuthally orthogonal direction was performed. Upon the orthogonal LPL irradiation, the scattering peaks of the PBMA cylinders a

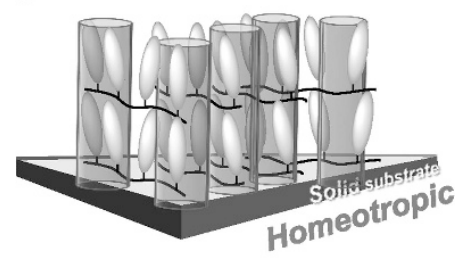

Mixing

PBMA- $b-\mathrm{PAz}$
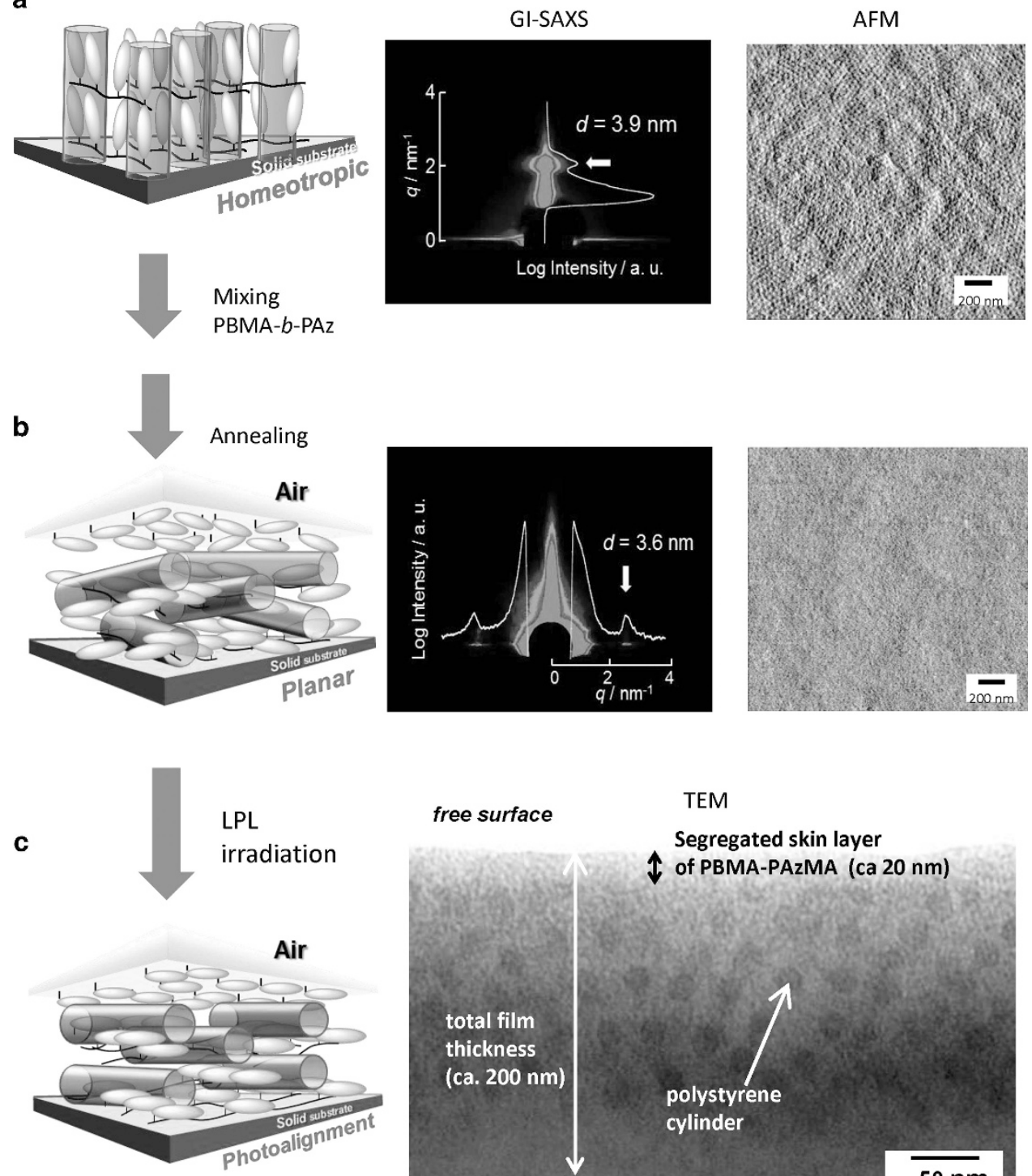

GI-SAXS

Log Intensity / a. u
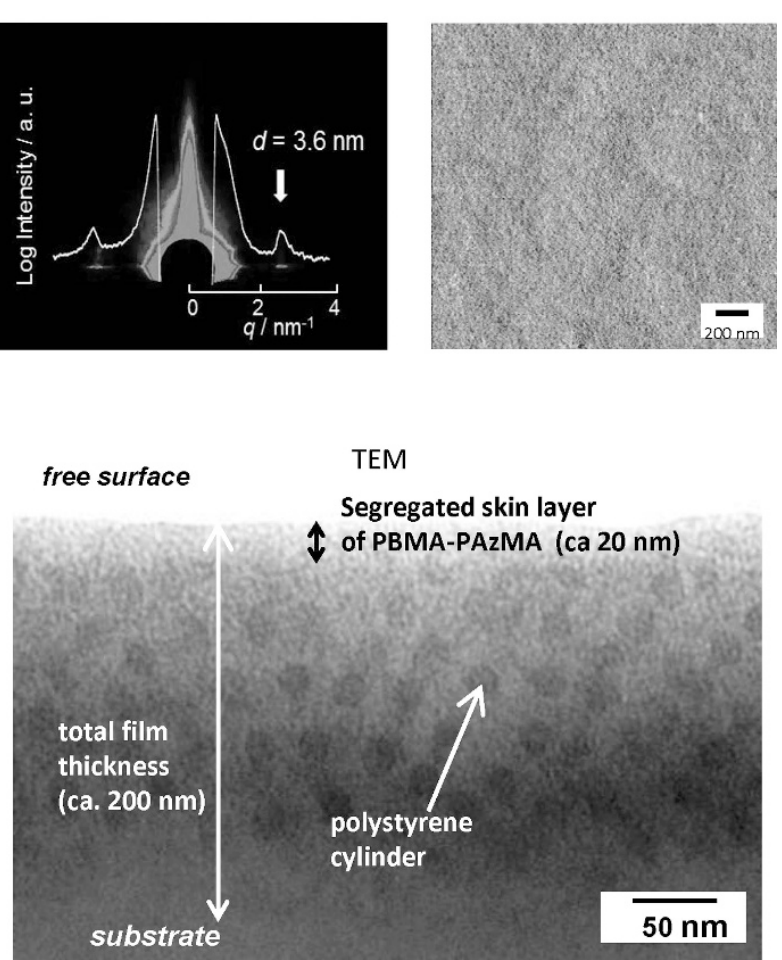

TEM

Segregated skin layer

of PBMA-PAZMA (ca $20 \mathrm{~nm}$ )

Figure 13 Schematic illustrations, grazing incidence angle X-ray scattering (GI-SAXS), atomic force microscopic (AFM) and transmission electron microscopic (TEM) data for a series of in-plane photoalignments of PS- $b$-PAz films via surface segregation of poly(butyl methacrylate) (PBMA)- $b$-PAz. (a) PS- $b$-PAz film without the addition of PBMA- $b$-PAz. (b) PS- $b$-PAz film obtained by the addition of 10 weight $\%$ of PBMA-b-PAz and annealing (case $f$ in Figure 4). (c) Photoaligned PBMA-b-PAz obtained by linearly polarized light (LPL) irradiation. For explanations of the GI-SAXS, AFM and TEM data, see the text. Adapted with permission. ${ }^{127}$ Copyright 2013, John Wiley \& Sons. A full color version of this figure is available at Polymer Journal online. 
(spacing $d=27 \mathrm{~nm}$ ), observed at a proper direction, and the smectic layers of azobenzene mesogens $(d=3.4 \mathrm{~nm})$ at the orthogonal direction disappeared quickly, within $40 \mathrm{~s}$ (Figure 12d). The enhancement of the peak at the orthogonal directions was observed after $50 \mathrm{~s}$ and gradually increased until $200 \mathrm{~s}$ to reach a saturated level (Figure 12e). Importantly, the time constants of the processes for the different size features were the same. We initially anticipated that the LC photoresponsive smectic layer of smaller size would reorient first, and then the PBMA cylinder of larger size would evolve at later stages. However, the results contradict this assumption and suggest that the reorienting process proceeds in a highly cooperative and synchronized manner between the two different hierarchical structures.

\section{PHOTOALIGNMENT OF BLOCK COPOLYMER FILMS VIA FREE SURFACE SEGREGATION}

As mentioned above, the azobenzene mesogens and MPS cylinder domains of PBMA-PAz films are always directed parallel to the substrate under annealing conditions. This behavior is unusual (see explanations for Figure 3). Further explorations have revealed that the segregated PBMA block at the topmost surface (free (air) surface) is responsible for the planar molecular orientation. The lower surface tension and high flexibility of the PBMA block result in segregation to the free surface. Thus, interfaces between blocks are preferentially formed parallel to the free surface.

Based on this knowledge, PBMA- $b$-PAz was expected to serve as a surface active polymer in a PS- $b-\mathrm{PAz}$ film. Fukuhara et al. ${ }^{127}$ demonstrated that a PS- $b$-PAz film with vertically aligned PS MPS cylinders can be converted to a planar orientation by mixing in a small amount of PBMA- $b$-PAz and then annealing (case $\mathrm{f}$ in Figure 4). Coverage of the segregated PBMA- $b-\mathrm{PAz}$ at the free surface of PS- $b$ $\mathrm{PAz}$ is responsible for this orientational inversion. Once this planar orientation is formed, the photoalignment of PS cylinders can be readily achieved by LPL irradiation. A schematic of this process is shown in Figure 13 along with GI-SAXS data, atomic force microscopic images, and a transmission electron microscopic image. Without PBMA- $b-\mathrm{PAz}$, the annealing of the PS- $b-\mathrm{PAz}$ film at $130{ }^{\circ} \mathrm{C}$ produces homeotropically aligned mesogens and PS cylinders (Figure 13a). The spacing $(d=3.9 \mathrm{~nm})$ of the smectic layer of azobenzene mesogens was found in the out-of-plane direction. In the atomic force microscopic measurements, a cylinder array with an average dot-to-dot distance of $47 \mathrm{~nm}$ was observed on the surface (Figure 13a). Mixing in 10 weight \% of PBMA- $b-\mathrm{PAz}$ and subsequently annealing the film resulted in markedly different data. In the GI-SAXS measurement, layer periodicity was observed in the in-plane direction with $d=3.6 \mathrm{~nm}$, and no characteristic features were observed by atomic force microscopic (Figure 13b). These data indicate that the mesogens and PS cylinders were oriented parallel with the substrate, and an amorphous layer of PBMA block was located on the topmost surface. The cross-section of the photoaligned film after irradiation with LPL at $95^{\circ} \mathrm{C}$ was observed by transmission electron microscopic. This transmission electron microscopic image clearly shows the existence of a segregated skin layer $(\sim 20 \mathrm{~nm}$ thickness) of PBMA- $b-\mathrm{PAz}$ on the air side. The thickness of the skin layer was approximately one-tenth of the total thickness, suggesting that PBMA- $b-\mathrm{PAz}$ was almost fully segregated to the free surface by annealing.

\section{COMMAND SURFACE EFFECT FROM THE FREE SURFACE}

In the above case, photoalignable azobenzene-containing polymer films were used. The next challenge was to exert photoalignment for non-photoresponsive LC polymers using a skin layer existing on the free surface. This approach can provide a new concept for the command surface effect. To date, surface-mediated photoalignments have been achieved with photoresponsive polymer films on solid substrates (Figure 14a). In contrast, the command surface effect from the free surface is a totally new concept (Figure 14b).

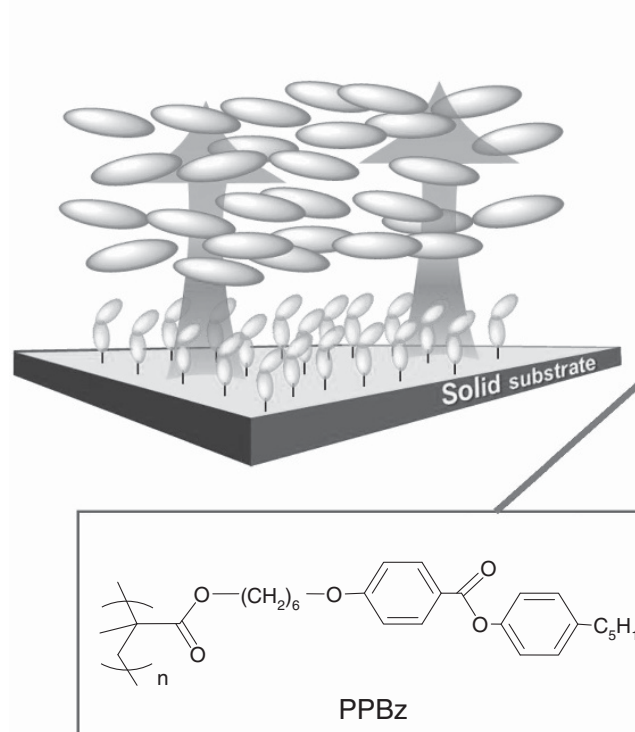

b
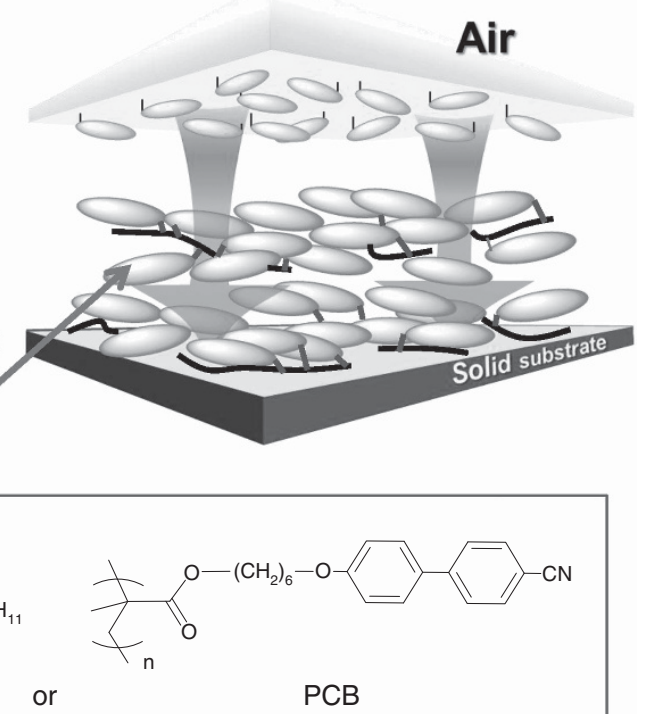

Figure 14 Schematic illustrations of photoalignment control using surface photoreactions. (a) Alignment control of liquid crystal (LC) molecules using surface photoreactions from the solid substrate side (command surface effect). (b) New proposed method to exert a command effect with a photoresponsive skin layer on the free (air) surface in polymer LC films. Adapted with permission. ${ }^{128}$ Copyright 2014 , Nature Publishing Group. A full color version of this figure is available at Polymer Journal online. 


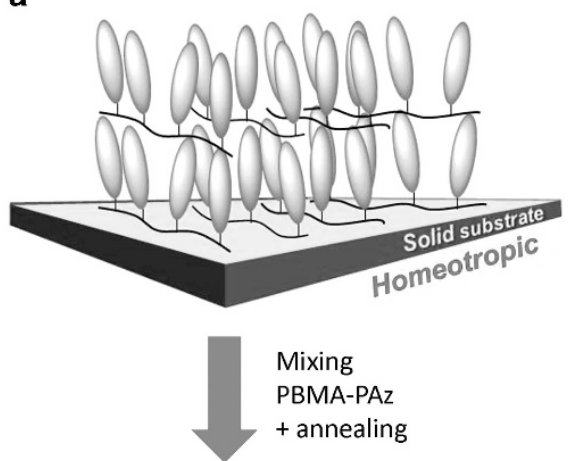

b

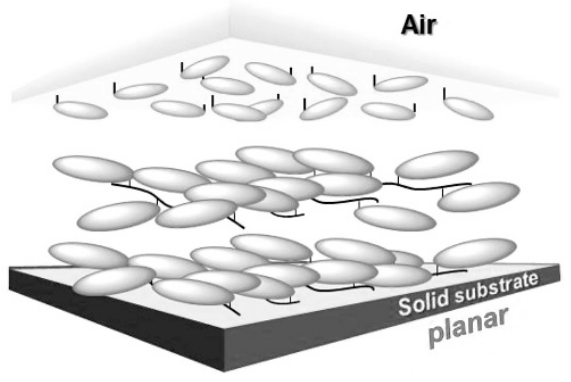

LPL

irradiation

c

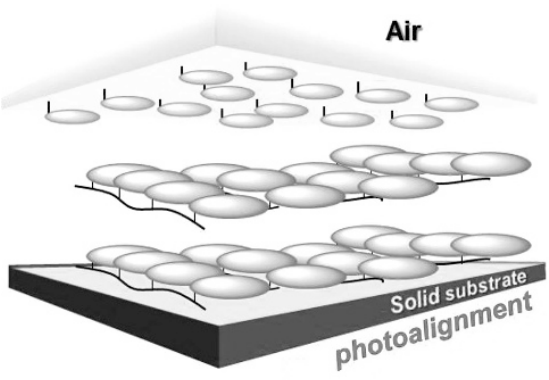

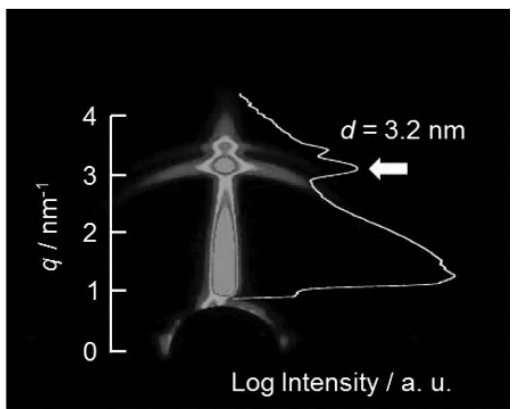
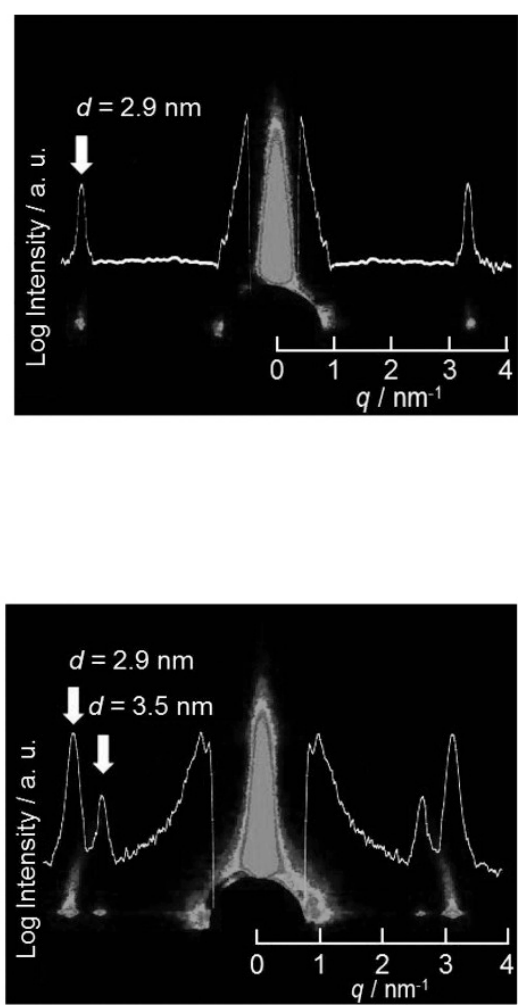

Figure 15 Schematic illustrations and grazing incidence angle X-ray scattering (GI-SAXS) data for a series of in-plane photoalignments of phenyl benzoate (PPBz) films via surface segregation of poly(butyl methacrylate) (PBMA)-b-PAz. (a) PPBz film without the addition of PBMA-b-PAz. (b) Random planar alignment of the PPBz film obtained by the addition of 3 weight \% of PBMA- $b$-PAz and subsequent annealing (case $f$ in Figure 4). (c) Homogeneous photoalignment of the film in $\mathbf{b}$ after linearly polarized light (LPL) irradiation. For explanations of the GI-SAXS analysis, see the text. Adapted with permission. ${ }^{128}$ Copyright 2014, Nature Publishing Group. A full color version of this figure is available at Polymer Journal online.

Fukuhara et al. ${ }^{128}$ showed that the photoresponsive skin layer of PBMA- $b-\mathrm{PAz}$ functions as a free-surface command layer for side chain LC polymer films containing a phenyl benzoate $(\mathrm{PPBz})$ or cyanobiphenyl side chain (chemical structures shown in Figure 14). The procedures were the same as described for the PS- $b$-PAz. Schematic drawings of the mesogen orientations are displayed in Figure 15 along with GI-SAXS data. In a pure PPBz film after annealing, the mesogens were oriented homeotropically, as expected (Figure 15a). The smectic layer of periodicity of the PPBz mesogens was observed in the out-of-plane direction with $d=3.2 \mathrm{~nm}$. By incorporating 3 weight $\%$ of PBMA- $b-\mathrm{PAz}$ and then annealing, X-ray scattering peaks were only observed in the in-plane direction $(d=2.9 \mathrm{~nm})$, indicating inversion to a random planar alignment of the mesogens (Figure 15b). Following homogeneous photoalignment with LPL, the in-plane peak became clearer, and the layer spacing ascribed to the azobenzene mesogen of PBMA- $b-\mathrm{PAz}$ with $d=3.5 \mathrm{~nm}$ was also observed. Various types of substrates can be used for this procedure. Inorganic substrates, such as silica plates with either hydrophilic or hydrophobic surfaces, and flexible polymer films can be used. This fact suggests the wide applicability of this method for device fabrication. The superior influence of the free surface has also been suggested for PEO-based block copolymer films. It was found that the vertical orientation of PEO MPS cylinders is insensitive to the surface energy (contact angle of water ranging $<5^{\circ}-85^{\circ}$ ) of the substrate surface. $^{129}$ 


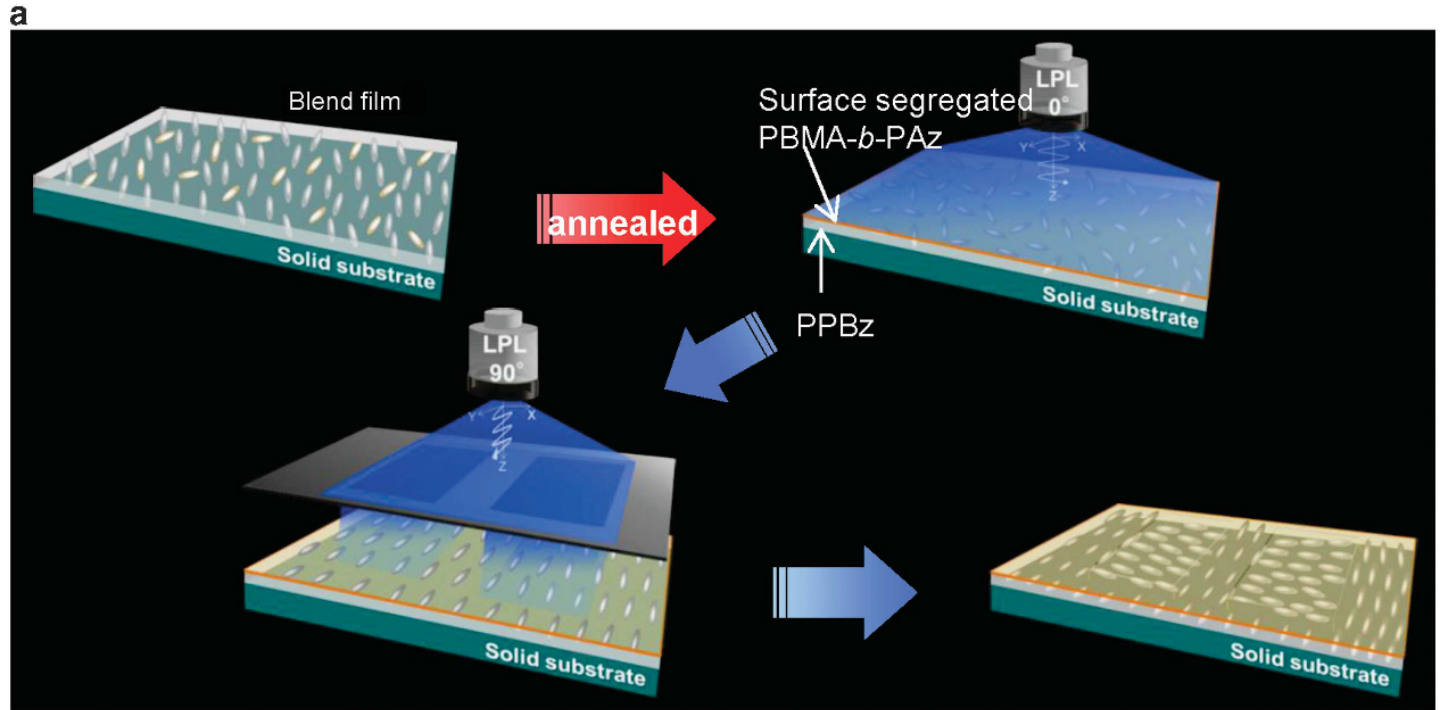

b

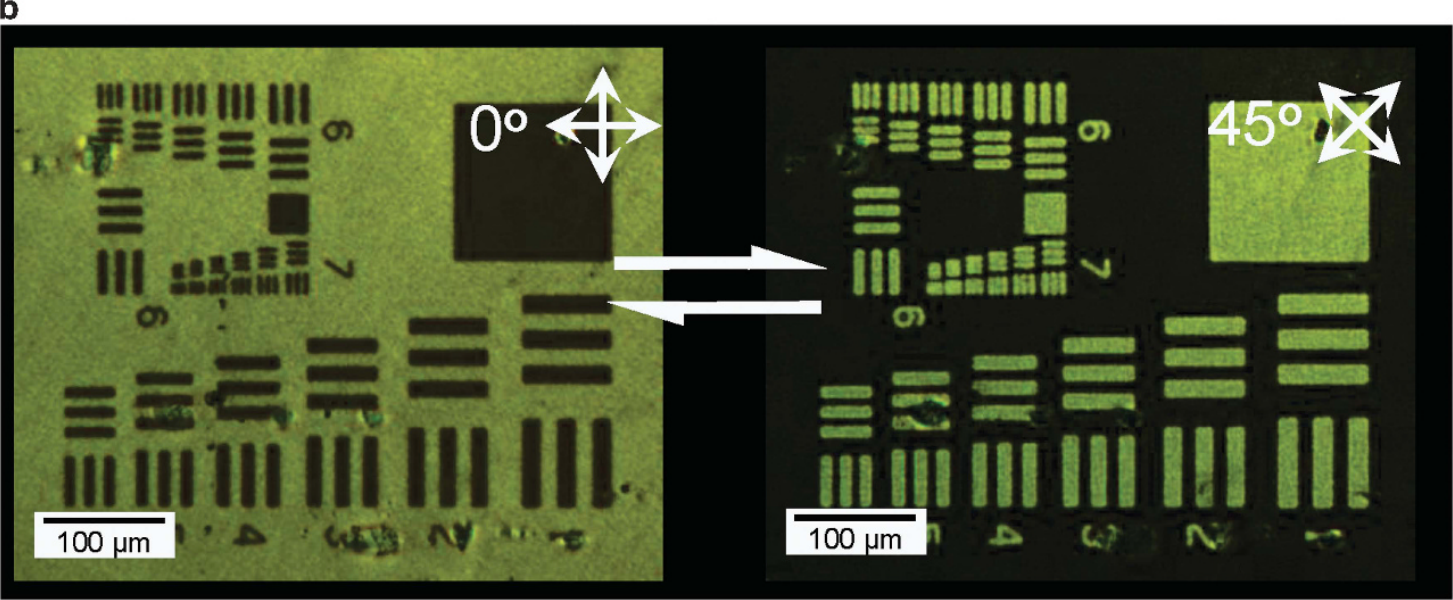

Figure 16 Planar-planar mode orientation patterning by linearly polarized light (LPL) irradiation. (a) Scheme showing the procedures for the in-plane photopatterning of the side chain polymer films. (b) Polarized optical microscopic (POM) images under crossed polarizers that are rotated $45^{\circ}$ from each other. Note that the positive and negative tone patterns are reversed. Adapted with permission. ${ }^{128}$ Copyright 2014, Nature Publishing Group.

Photopatterning of in-plane alignment has also been achieved (Figure 16). ${ }^{128}$ In this process, LPL was first used to irradiate an entire film area, followed by a subsequent irradiation with LPL in the orthogonal direction, as shown in Figure 16a. This procedures provided patterned in-plane alignment of the $\mathrm{PPBz}$ mesogens (Figure 16b). In the polarized optical microscopic observations, rotation of the crossed polarizers led to an alternation of the bright and dark tones. This result indicated that this patterning is rewritable. It should also be noted that non-photoresponsive mesogens up to $10 \mu \mathrm{m}$ thick can be oriented by a photoresponsive PBMA- $b$-PAz skin layer of $\sim 20 \mathrm{~nm}$ thick, existing at the free surface. Thus, the photoresponsive skin layer can command orientations of a nonphotoresponsive mesogen layer that is $\sim 500$ times thicker.

An interesting feature of free surface control is that printing methods can be applied on LC films. In other words, printing methods can be used to realize free surface control. After the preparation of a $\mathrm{PPBz}$ film, inkjet printing of PBMA- $b-\mathrm{PAz}$ was conducted, as schematically illustrated in Figure 17a. Subsequently, annealing and LPL irradiation were performed in the same manner. In this command system, a resolution of $1 \mu \mathrm{m}$ can be readily obtained
(Figure 17b), based on the birefringence observation made under the crossed polarizers. In contrast to the photopatterning in Figure 16, the patterning was achieved between the alignment of the homeotropic and homogeneous planar modes in the unprinted and printed areas, respectively. Thus, the unprinted regions were observed as a dark field, irrespective of the rotation of the crossed polarizers. An example is shown in Figure 17c. The rotation of the crossed polarizers by $45^{\circ}$ led to the appearance and disappearance of the printed figure because the PPBz mesogens were homogeneously photoaligned in the printed area. In the printing method, drawings can be made of any desired figure. Thus, the block copolymer of PBMA- $b$-PAz can be regarded as a 'command surface ink.'

\section{SUMMARY}

At the free surface of calamitic LC films, the rod-shaped molecules tend to be oriented vertically to the boundary plane. This molecular orientation can be the major reason for rod-like mesogens, such as azobenzene, being oriented normal to the film (substrate) plane in side chain LC polymer films. This situation is unfavorable for allowing effective photoreactions because the light irradiation is 
a

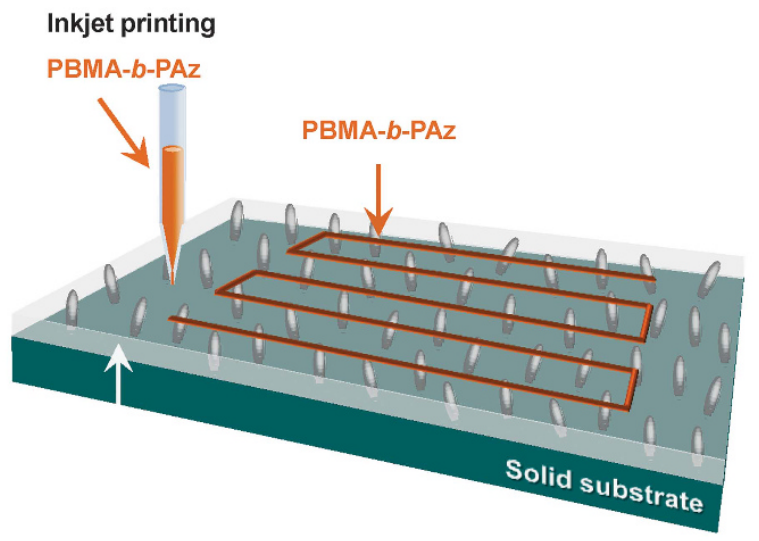

b

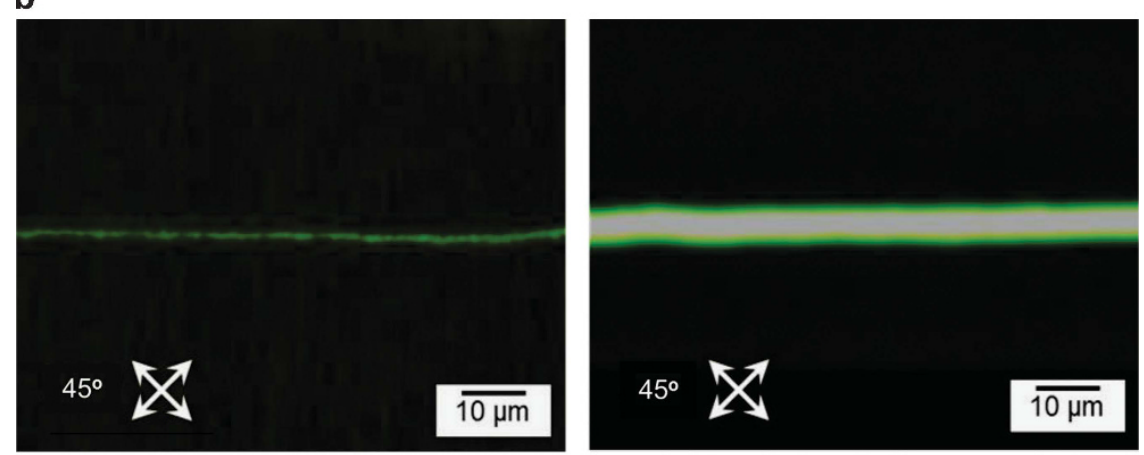

C

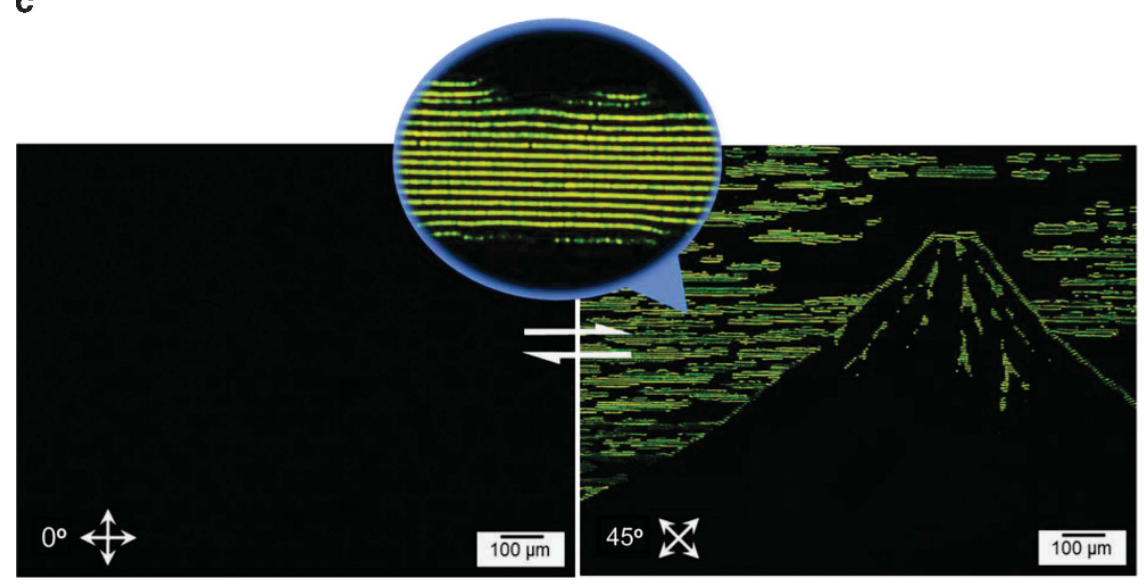

Figure 17 Homeotropic-planar orientation mode patterning via inkjet printing. (a) Scheme of inkjet printing onto a phenyl benzoate (PPBz) thin film. (b) Photoaligned PPBz films in printed regions, commanded by a surface skin layer of poly(butyl methacrylate) (PBMA)- $b$-PAz and linearly polarized light (LPL) irradiation for 1-mm (left) and 5-mm (right) wide lines. (c) The appearance and disappearance of a birefringence patterning observed by polarized optical microscopic (POM) under crossed polarizers. The emergence of the image is fully switched by rotating the polarizers at $45^{\circ}$. Adapted with permission. ${ }^{128}$ Copyright 2014, Nature Publishing Group.

usually performed with a normal incidence. The horizontal orientation of azobenzene mesogens is desired. However, particular strategies are needed. This review first focused on this point and summarized the strategies for realizing the in-plane orientation of azobenzene mesogens. A pre-formed in-plane orientation is typically attained by surface-grafted chains of sufficiently high two-dimensional density. When block copolymers made by two-step surface-initiated ATRP are used, the motions are coupled with the segmental mobility of the amorphous polymer beneath the LC layer. Photoalignment processes are achieved via the cooperative motion of photoresponsive molecules at the molecular level, and this motion can be further converted to larger, hierarchical mesoscopic structures in block copolymer films. The photoinduced reorienting process occurs through the strong cooperative motion of the azobenzene LC units and the mesoscopic MPS amorphous domains. Through these studies, the crucial role of the free surface in mesogen orientation has been recognized. For LC polymer films, a photoresponsive skin layer can be readily deposited by surface segregation phenomenon or inkjet printing. In free-surface command systems, azimuthal photocontrols can be achieved up to a surprisingly large thickness $(\sim 10 \mu \mathrm{m})$ by using a 20 -nm skin layer of 
photoresponsive block copolymer. It is envisaged that new approaches introduced in this article can lead to new possibilities in LC processing and the fabrication of new optical devices.

\section{ACKNOWLEDGEMENTS}

I thank Emeritus Professor Kunihiro Ichimura of the Tokyo Institute of Technology for his continuing encouragement in the study of LC photoalignment. I wish to express particular thanks to Associate Professor Shusaku Nagano of Nagoya University for his great contributions to the projects. I also acknowledge the support provided by Associate Professor Yukikazu Takeoka and Assistant Professor Mitsuo Hara of Nagoya University. I am indebted for the great experimental accomplishments of Dr Takayuki Uekusa, Dr Yuichi Morikawa, Dr Hafiz Ashraful Haque, Dr Kei Fukuhara, Ms Masami Sano, and many other students at Nagoya University. The research also involved collaborative projects with Professor Tomokazu Iyoda of the Tokyo Institute of Technology for the SRG formation of block copolymer and Assistant Professor Yuya Shinohara and Professor Yoshiyuki Amemiya of the University of Tokyo for the synchrotron SAXS measurements. The work was supported by a Grant-in-Aid for Priority Aria (Photochromism no. 471) from the MEXT, a Grant-in-Aid for Scientific Research (S: 23225003) from JSPS, and the PRESTO Program from JST to SN.

1 Zhao, Y. \& Ikeda, T. Smart Light-Responsive Materials (John Wiley \& Sons, Hoboken, USA, 2009).

2 Ichimura, K. Photoalignment of liquid-crystal systems. Chem. Rev. 100, 1847-1873 (2000)

3 O'Neill, M. \& Kelly, S. M. Photoinduced surface alignment for liquid crystal displays. J. Phys. D: Appl. Phys. 33, R67-R84 (2000).

4 Yaroshchuk, O. \& Reznikov, Y. Photoalignment of liquid crystals: basics and current trends. J. Mater. Chem. 22, 286-300 (2012).

5 Seki, T., Nagano, S. \& Hara, M. Versatility of photoalignment techniques: from nematics to a wide range of functional materials. Polymer 54, 6053-6072 (2013)

6 Chigrinov, V., Kozenkov, V. M. \& Kwok, H.-S. Photoalignment of Liquid Crystalline Materials, SID Series in Display Technology (John Wiley \& Sons, West Sussex, UK 2008).

7 Ikeda, T. Photomodulation of liquid crystal orientations for photonic applications J. Mater. Chem. 13, 2037-2057 (2003).

8 Ikeda, T., Horiuchi, S., Karanjit, D. B., Kurihara, S. \& Tazuke, S. Photochemica image storage in polymer liquid crystals. Chem. Lett. 17, 1679-1682 (1988).

9 Norikane, Y., Hirai, Y. \& Yoshida, M. Photoinduced isothermal phase transitions of liquid-crystalline macrocyclic azobenzenes. Chem. Commun. 47, 1770-1772 (2011).

10 Akiyama, H. \& Yoshida, M. Photochemically reversible liquefaction and solidification of single compounds based on a sugar alcohol scaffold with multi azo-arms. Adv. Mater. 24, 2353-2356 (2012).

11 Sato, M., Nagano, S. \& Seki, T. A photoresponsive liquid crystal based on (1-cyclohexenyl)phenyldiazene as a close analogue of azobenzene. Chem. Commun 45, 3792-3794 (2009).

12 Tanaka, D., Ishiguro, H., Shimizu, Y. \& Uchida, K. Thermal and photoinduced liquid crystalline phase transitions with a rod-disc alternative change in the molecula shape. J. Mater. Chem. 22, 25065-25071 (2012).

13 Natansohn, A. \& Rochon, P. Photoinduced motions in azo-containing polymers. Chem. Rev. 102, 4139-4176 (2002).

14 Stumpe, J., Kulikovska, O., Goldenberg, L. M. \& Zakrevskyy, Y. in Smart LightResponsive Materials (eds Zhao, Y. \& Ikeda, T.) Ch. 2, 47-94 (John Wley \& Sons, Hoboken, USA, 2009).

15 Shishido, A. Rewritable holograms based on azobenzene-containing liquid-crystalline polymers. Polym. J. 42, 525-533 (2010).

16 Kawatsuki, N. Photoalignment and photoinduced molecular reorientation of photosensitive materials. Chem. Lett. 40, 548-554 (2011).

17 Bobrovsky, A., Ryabchun, A. \& Shibaev, V. Liquid crystals photoalignment by films of side-chain azobenzene-containing polymers with different molecular structure. J. Photochem. Photobiol. A: Chem. 218, 137-142 (2011).

18 Priimagi, A., Ogawa, K., Virkki, M., Mamiya, J., Kauranen, M. \& Shishido, A. Highcontrast photoswitching of nonlinear optical response in crosslinked ferroelectric liquid-crystalline polymers. Adv. Mater. 24, 6410-6415 (2012).

19 Seki, T. Meso- and microscopic motions in photoresponsive liquid crystalline polymer films. Macromol. Rapid Commun. 35, 271-290 (2014).

20 Ubukata, T., Seki, T. \& Ichimura, K. Surface relief gratings in host-guest supramolecular materials. Adv. Mater. 12, 1675-1678 (2000).

21 Seki, T. Photoresponsive self-assembly motions in polymer thin films. Curr. Opin. Solid State Mater. Sci. 10, 241-248 (2006)
22 Zettsu, N., Ogasawara, T., Arakawa, R., Nagano, S., Ubukata, T. \& Seki, T. Highly photosensitive surface relief gratings formation in a liquid crystalline azobenzene polymer: new implications for the migration process. Macromolecules 40, 4607-4613 (2007)

23 Zettsu, N., Ogasawara, T., Mizoshita, N., Nagano, S. \& Seki, T. Photo-triggered surface relief grating formation in supramolecular liquid crystalline polymer systems with detachable azobenzene unit. Adv. Mater. 20, 516-521 (2008).

24 Seki, T. Smart photoresponsive polymer systems organized in two dimensions. Bull. Chem. Soc. Jpn 80, 2084-2109 (2007).

25 Isayama, J., Nagano, S. \& Seki, T. Phototriggered mass migrating motions in liquid crystalline azobenzene polymer films with systematically varied thermal properties. Macromolecules 43, 4105-4112 (2010).

26 Li, W., Dohi, T., Hara, M., Nagano, S., Haba, O., Yonetake, K. \& Seki, T. Phototriggered mass migration consorted with surface dewetting in thin films of a liquid crystalline azobenzene-containing dendrimer. Macromolecules 45, 6618-6627 (2012)

27 Park, J.-W., Nagano, S., Yoon, S.-J., Dohi, T., Seo, J., Seki, T. \& Park, S. Y. High contrast fluorescence patterning in cyanostilbene-based crystalline thin films: crystallization-induced mass flow via a photo-triggered phase transition. Adv. Mater. 26, 1354-1359 (2014).

28 Priimagi, A. \& Shevchenko, A. Azopolymer-based micro- and nanopatterning for photonic applications. J. Polym. Sci. Part B: Polym. Phys. 52, 163-182 (2014).

29 Ichimura, K., Oh, S.-K. \& Nakagawa, M. Light-driven motion of liquids on a photoresponsive surface. Science 288, 1624-1626 (2000).

30 Oh, S.-K., Nakagawa, M. \& Ichimura, K. Photocontrol of liquid motion on an azobenzene monolayer. J. Mater. Chem. 12, 2262-2269 (2002).

31 Yang, D., Piech, M., Bell, N. S., Gust, D., Vail, S., Garcia, A. A., Schneider, J., Park, C.-D., Hayes, M. A. \& Picraux, S. T. Photon control of liquid motion on reversibly photoresponsive surfaces. Langmuir 23, 10864-10872 (2007).

32 Seki, T., Sekizawa, H., Morino, S.-y. \& Ichimura, K. Inherent and cooperative photomechanical motions in monolayers of an azobenzene containing polymer at the air-water interface. J. Phys. Chem. B 102, 5313-5321 (1998).

33 Seki, T., Kojima, J. \& Ichimura, K. Multifarious photoinduced morphologies in monomolecular films of azobenzene side chain polymer on mica. Macromolecules $\mathbf{3 3}$ 2709-2717 (2000)

34 Kadota, S., Aoki, K., Nagano, S. \& Seki, T. Photocontrolled microphase separation of block copolymers in two dimensions. J. Am. Chem. Soc. 127, 8266-8267 (2005).

35 Aoki, K., Iwata, T., Nagano, S. \& Seki, T. Light-directed anisotropic reorientation of mesopatterns in block copolymer monolayers. Macromol. Chem. Phys. 211, 2484-2489 (2010)

36 Yu, Y., Nakano, M. \& Ikeda, T. Directed bending of a polymer film by light. Nature 425, 145 (2003).

37 Ikeda, T., Mamiya, J.-i. \& Yu, Y. Photomechanics of liquid-crystalline elastomers and other polymers. Angew. Chem. Int. Ed. 46, 506-528 (2007).

38 Barrett, C. J., Mamiya, J., Yager, K. G. \& Ikeda, T. Photo-mechanical effects in azobenzene-containing soft materials. Soft Matter 3, 1249-1261 (2007).

39 Ikeda, T. \& Ube, T. Photomobile polymer materials: from nano to macro. Mater. Today 14, 480-487 (2011).

40 Yamada, M., Kondo, M., Miyasato, R., Naka, Y., Mamiya, J., Kinoshita, M., Shishido, A., Yu, Y., Barrett, C. J. \& Ikeda, T. Photomobile polymer materials-various threedimensional movements. J. Mater. Chem. 19, 60-62 (2009).

41 Yu, H. \& Ikeda, T. Photocontrollable liquid-crystalline actuators. Adv. Mater. 23, 2149-2180 (2011).

42 Camacho-Lopez, M., Finkelmann, H., Palffy-Muhoray, P. \& Shelley, M. Fast liquidcrystal elastomer swims into the dark. Nat. Mater. 3, 307-310 (2004).

43 White, T. J. Light to work transduction and shape memory in glassy, photoresponsive macromolecular systems: trends and opportunities. J. Polym. Sci. Pt B: Polym. Phys. 50, 877-880 (2012).

44 Wei, J. \& Yu, Y. Photodeformable polymer gels and crosslinked liquid-crystalline polymers. Soft Matter 8, 8050-8059 (2012).

45 Mamiya, J. Photomechanical energy conversion based on cross-linked liquid-crystalline polymers. Polym. J. 45, 239-246 (2013).

46 van Oosten, C. L., Bastiaansen, C. W. M. \& Broer, D. J. Printed artificial cilia from liquid-crystal network actuators modularly driven by light. Nat. Mater. 8, 677-682 (2009).

47 Ichimura, K., Suzuki, Y., Seki, T., Hosoki, A. \& Aoki, K. Reversible change in alignment mode of nematic liquid crystals regulated photochemically by command surfaces modified with an azobenzene monolayer. Langmuir 4, 1214-1216 (1988)

48 Gibbons, W. M., Shannon, P. J., Sun, S.-T. \& Swetlin, B. J. Surface-mediated alignment of nematic liquid crystals with polarized laser light. Nature 351, 49-50 (1991).

49 Dyadyusha, A., Kozinkov, V., Marusii, T., Reznikov, Y., Reshetnyak, V. \& Khizhnyak, A Optically induced planar orientation of nematic liquid crystals on anisotropic surfaces without microrelief. Ukr. Fiz. Z 36, 1059-1062 (1991).

50 Schadt, M., Schmitt, K., Kozinkov, V. \& Chigrinov, V. Surface-induced paralle alignment of liquid crystals by linearly polymerized photopolymers. Jpn J. Appl. Phys. 31, 2155-2164 (1992).

51 Kawanishi, Y., Tamaki, T., Sakuragi, M., Seki, T., Suzuki, Y. \& Ichimura, K. Photochemical induction and modulation of nematic homogeneous alignment by 
the polarization photochromism of surface azobenzenes. Langmuir 8, 2601-2604 (1992).

52 Seki, T., Sakuragi, M., Kawanishi, Y., Suzuki, Y., Tamaki, T., Fukuda, R. \& Ichimura, K. 'Command surfaces' of Langmuir-Blodgett films. Photoregulations of liquid crystal alignment by molecularly tailored surface azobenzene layers. Langmuir 9, 211-218 (1993)

53 Seki, T., Fukuda, R., Tamaki, T. \& Ichimura, K. Alignment photoregulation of liquid crystals on precisely area controlled azobenzene Langmuir-Blodgett monolayers. Thin Solid Films 243, 675-678 (1994).

54 Ichimura, K., Furumi, S., Morino, S., Kidowaki, M., Nakagawa, M., Ogawa, M. \& Nishiura, Y. Photocontrolled orientation of discotic liquid crystals. Adv. Mater. 12, 950-953 (2000).

55 Furumi, S., Kidowaki, M., Ogawa, M., Nishimura, Y. \& Ichimura, K. Surface-mediated photoalignment of discotic liquid crystals on azobenzene polymer films. J. Phys. Chem. B 109, 9245-9254 (2005).

56 Ichimura, K., Momose, M., Kudo, K., Akiyama, H. \& Ishizuki, N. Surface-assisted photolithography to form anisotropic dye layers as a new horizon of command surfaces. Langmuir 11, 2341-2343 (1995).

57 Ichimura, K., Fujiwara, T., Momose, M. \& Matsunaga, D. Surface-assisted photoalignment control of lyotropic liquid crystals. Part 1. Characterisation and photoalignment of aqueous solutions of a water-soluble dye as lyotropic liquid crystals. J. Mater. Chem. 12, 3380-3386 (2002).

58 Matsunaga, D., Tamaki, T., Akiyama, H. \& Ichimura, K. Photofabrication of micro-patterned polarizing elements for stereoscopic displays. Adv. Mater. 14, 1477-1480 (2002)

59 Kidowaki, M., Fujiwara, T. \& Ichimura, K. Surface-assisted photomanipulation of orientation of a polymer liquid crystal. Chem. Lett. 28, 643-644 (1999).

60 Fukuda, K., Seki, T. \& Ichimura, K. Photoorientation of poly(di- $n$-hexylsilane) by azobenzene monolayer 2. Structural optimization of the surface azobenzene monolayer. Macromolecules 35, 1951-1957 (2002).

61 Sakamoto, K., Miki, K., Misaki, M., Sakaguchi, K., Hijikata, Y., Chikamatsu, M. \& Azumi, R. Highly polarized polymer-based light-emitting diodes fabricated by using very thin photoaligned polyimide layers. J. Appl. Phys. 107, 113108 (2010).

62 Fujiwara, T., Locklin, J. \& Bao, Z. Solution deposited liquid crystalline semiconductors on a photoalignment layer for organic thin-film transistors. Appl. Phys. Lett. 90, 232108 (2007).

63 Kawashima, Y, Nakagawa, M., Seki, T. \& Ichimura, K. Photoorientation of mesostructured silica via hierachical multiple transfer. Chem. Mater. 14, 2842-2844 (2002).

64 Kawashima, Y., Nakagawa, M., Ichimura, K. \& Seki, T. Photo-orientation of mesoporous silica materials via transfer from azobenzene-containing polymer monolayer. J. Mater. Chem. 14, 328-335 (2004).

65 Fukumoto, H., Nagano, S., Kawatsuki, N. \& Seki, T. Photo-orientation of mesoporous silica thin films on photo-crosslinkable polymer film. Adv. Mater. 17, 1035-1039 (2005)

66 Fukumoto, H., Nagano, S., Kawatsuki, N. \& Seki, T. Photoalignment behavior of mesoporous silica thin films synthesized on a photo-crosslinkable polymer film. Chem. Mater. 18, 1226-1234 (2006).

67 Hara, M., Nagano, S., Mizoshita, N. \& Seki, T. Chromonic/silica nanohybrids. synthesis and macroscopic alignment. Langmuir 23, 12350-12355 (2007).

68 Hara, M., Nagano, S., Kawatsuki, N. \& Seki, T. Photoalignment and patterning of chromonic/silica nanohybrid on photocrosslinkable polymer thin film. J. Mater. Chem. 18, 3259-3263 (2008).

69 Miyachi, K., Kobayashi, K., Yamada, Y. \& Mizushima, S. The world's first photo alignment LCD technology applied to generation ten factory. SID Symp. Digest Tech. Papers 41, 579-582 (2010).

70 Chigrinov, V. Photoaligning and photopatterning-a new challenge in liquid crystal photonics. Crystals 3, 149-162 (2013).

71 Kimura, H. \& Nakano, H. Statistical theory of surface tension and molecular orientations at the free surface in nematic liquid crystals. J. Phys. Soc. Jpn 54 1730-1736 (1985)

72 Scaramuzza, N., Berlic, C., Barna, E. S., Strangi, G., Barna, V. \& Ionescu, A. Molecular simulation of the free surface order in NLC samples. J. Phys. Chem. B 108, 3207-3210 (2004).

73 Faetti, S. \& Fronzoni, L. Molecular orientation in nematic liquid crystal films with two free surfaces. Solid State Commun. 25, 1087-1090 (1978).

74 Ocko, B. M., Braslau, A., Pershan, P. S., Als-Nielsen, J. \& Deutsch, M. Quantized layer growth at liquid-crystal surfaces. Phys. Rev. Lett. 57, 94-97 (1986).

75 Feringa, B. L. The art of building small: from molecular switches to molecular motors. J. Org. Chem. 72, 6635-6652 (2007).

76 Tamaoki, N. \& Kamei, T. Reversible photo-regulation of the properties of liquid crystals doped with photochromic compounds. J. Photochem. Photobiol. C: Photochem. Rev. 11, 47-61 (2010).

77 Muraoka, T. \& Kinbara, K. Development of photoresponsive supramolecular machines inspired by biological molecular systems. J. Photochem. Photobiol. C: Photochem. Rev. 13, 136-147 (2012).

78 Ichimura, K., Hayashi, Y., Akiyama, H., Ikeda, T. \& Ishizuki, N. Photo-optical liquid crystal cells driven by molecular rotors. Appl. Phys. Lett. 63, 449-451 (1993).

79 Akiyama, H., Kudo, K. \& Ichimura, K. Command surfaces, 10. Novel polymethacrylates with laterally attached azobenzene groups displaying photoinduced optical anisotropy. Macromol. Rapid Commun. 16, 35-41 (1995).
80 Akiyama, H., Momose, M., Ichimura, K. \& Yamamura, S. Surface-selective modification of poly(vinyl alcohol) films with azobenzenes for in-plane alignment photocontrol of nematic liquid crystals. Macromolecules 28, 288-293 (1995).

81 Li, M.-H., Auroy, P. \& Keller, P. An azobenzene-containing side-on liquid crystal polymer. Liq. Cryst. 27, 1497-1502 (2000).

82 Gu, H.-W., Xie, P., Fiu, P.-D., Ahang, T.-Y. \& Zhang, R.-B. Influence of side-chain structure and irradiation condition on photoalignment of laddre-like polysiloxane films. Adv. Funct. Mater. 15, 125-130 (2005).

83 Petr, M. \& Hammond, P. T. Room temperature rapid photoresponsive azobenzene side chain liquid crystal polymer. Macromolecules 44, 8880-8885 (2011).

84 Sakamoto, K., Usami, K., Kikegawa, M. \& Ushioda, S. Alignment of polyamic acid molecules containing azobenzene in the backbone structure: effects of polarized ultraviolet light irradiation and subsequent thermal imidization. J. Appl. Phys. 93, 1039 (2003)

85 Sakamoto, K., Usami, K., Sasaki, T., Uehara, Y. \& Ushioda, S. Pretilt angle of liquid crystals on polyimide films photo-aligned by single oblique angle irradiation with unpolarized light. Jpn J. Appl. Phys. 45, 2705-2707 (2006).

86 Park, B., Jung, Y., Choi, H.-H., Hwang, H.-K., Kim., Y., Lee, S., Kang, S.-H., Kakimoto, M. \& Takezoe, H. Thermal and optical stabilities of photoisomerizable polyimide layers for nematic liquid crystal alignments. Jpn J. Appl. Phys. 37, 5663 (1998).

87 Hahm, S. G., Lee, S. W., Lee, T. J., Cho, S. A., Chae, B., Jung, Y. M., Kim, S. Bin. \& Ree, M. UV-driven switching of chain orientation and liquid crystal alignment in nanoscale thin films of a novel polyimide bearing stilbene moieties in the backbone. J. Phys. Chem. B 112, 4900-4912 (2008).

88 Song, S., Watabe, M., Adachi, T., Kobae, T., Chen, Y., Kawabata, M., Ishida, Y., Takahara, S. \& Yamaoka, T. Photoalignment films of polyesters with photoreactive main chain. Jpn J. Appl. Phys. 37, 2620 (1998).

89 Chae, B., Lee, S. W., Ree, M. \& Kim, S. B. Molecular orientation of new photosensitive polyesters for liquid crystal alignment. Vibr. Spectroscopy 29, 69-72 (2002)

90 Maeshima, K., Song, S., Watabe, M., Tsushima, H., Kawabata, M., Sumiyoshi, I. Miyagawa, N., Takahara, S. \& Yamaoka, T. Photoalignment films of polyesters with photoreactive main chain; photodimerization of 4-[4-(2-carboxyvinylene)-phenylcarbonyloxy] cinnamate group. J. Photopolym. Sci. Technol. 12, 249-250 (1999).

91 Mihara, T. Photo-alignment properties of photo-crosslinked films of liquid crystalline polymers containing chalcone derivatives. Mol. Cryst. Liq. Cryst. 441, 185-200 (2005)

92 Li, X.-D., Zhong, Z.-X., Lee, S. H., Ghang, G. \& Lee, M.-H. Liquid crystal photoalignment using soluble photosensitive polyimide. Jpn J. Appl. Phys. 45, 906-908 (2006)

93 Peng, B., Johannsmann, D. \& Ruhe, J. Polymer brushes with liquid crystalline side chains. Macromolecules 32, 6759-6766 (1999).

94 Peng, B., Ruhe, J. \& Johannsmann, D. Homogeneously aligned liquid-crystal polymer brushes. Adv. Mater. 12, 821-824 (2000).

95 Hamelinck, P. J. \& Huck, W. T. S. Homeotropic alignment on surface-initiated liquid crystalline polymer brushes. J. Mater. Chem. 15, 381 (2005).

96 Uekusa, T., Nagano, S. \& Seki, T. Unique molecular orientation in a smectic liquid crystalline polymer film attained by surface-initiated graft polymerization. Langmuir 23, 4642-4645 (2007).

97 Tsujii, Y., Ohno, K., Yamamoto, S., Goto, A. \& Fukuda, T. Structure and properties of high-density polymer brushes prepared by surface-initiated living radical polymerization. Adv. Polym. Sci. 197, 1-45 (2006).

98 Uekusa, T., Nagano, S. \& Seki, T. Highly ordered in-plane photoalignment attained by the brush architecture of liquid crystalline azobenzene polymer. Macromolecules 42 , 312-318 (2009).

99 Camorani, P., Cristofolini, L., Fontana, M. P., Angiolini, L., Giorgini, L. \& Paris, F. Azo-containing polymer brushes: photoalignment and application as command surfaces. Mol. Cryst. Liq. Cryst. 502, 56-64 (2009).

100 Haque, H. A., Kakehi, S., Hara, M., Nagano, S. \& Seki, T. High-density liquidcrystalline azobenzene polymer brush attained by surface-initiated ring-opening metathesis polymerization. Langmuir 29, 7571-7575 (2013).

101 Haque, H. A., Nagano, S. \& Seki, T. Lubricant effect of flexible chain in the photoinduced motions of surface-grafted liquid crystalline azobenzene polymer brush. Macromolecules 45, 6095-6103 (2012).

102 Finkelmann, H., Ringsdorf, H. \& Wendorff, J. H. Model considerations and examples of enantiotropic liquid crystalline polymers. Polyreactions in ordered systems, 14. Makromol. Chem. 179, 273-276 (1978).

103 Haque, H. A., Nagano, S. \& Seki, T. Effect of flexible chain length on the photoorientation behavior of surface-grafted liquid crystalline azobenzene block Copolymer brush. Mol. Cryst. Liq. Cryst. 583, 10-20 (2013).

104 Haque, H. A., Hara, M., Nagano, S. \& Seki, T. Photoinduced in-plane motions of azobenzene mesogens affected by the flexibility of underlying amorphous chains. Macromolecules 46, 8275-8283 (2013).

105 Park, C., Yoon, J. \& Thomas, E. L. Enabling nanotechnology with self-assembled block copolymer patterns. Polymer 44, 6725-6760 (2003).

106 Luo, M. \& Epps, T. H. Directed block copolymer thin film self-Assembly: emerging trends in nanopattern fabrication. Macromolecules 46, 7567-7579 (2013).

107 Lazzari, M., Liu, G. \& Recommandoux, S. Block Copolymer in Nanoscience (WileyVCH, Weinheim, Germany, 2006).

108 Hamley, I. M. Developments in Block Copolymers Science and Technology (John Wiley \& Sons, Hoboken, USA, 2004) 
109 Tsui, O. K. \& Russell, T. P. Polymer Thin Films (World Scientific Publishing, Singapore, 2009).

110 Yamada, M., Hirao, A. Nakahama, S., Iguchi, T. \& Watanabe, J. Synthesis of side chain liquid crystalline homopolymers and block copolymers with well-defined structures by living anionic polymerization and their thermotropic phase behavior. Macromolecules 28, 50-58 (1995).

$111 \mathrm{Mao}, \mathrm{G}$. \& Ober, C. K. Block copolymers containing liquid crystalline segments. Acta Polymerica 48, 405-422 (1997).

112 Tian, Y., Watanabe, K., Kong, X., Abe, J. \& Iyoda, T. Synthesis, nanostructures, and functionality of amphiphilic liquid crystalline block copolymers with azobenzene moieties. Macromolecules 35, 3739-3747 (2002).

113 Komura, M., Watanabe, K., Iyoda, T., Yamada, T., Yoshida, H. \& Iwasaki, Y. Laboratory-GISAXS measurements of block copolymer films with highly ordered and normally oriented nanocylinders. Chem. Lett. 38, 408-409 (2009).

114 Asaoka, S., Uekusa, T., Tokimori, H., Komura, M., Iyoda, T., Yamada, T. \& Yoshida, H. Normally oriented cylindrical nanostructures in amphiphilic PEO-LC diblock copolymers films. Macromolecules 44, 7645-7658 (2011).

115 Zhao, Y., Qi, B., Tong, X. \& Zhao, Y. Synthesis of double side-chain liquid crystalline block copolymers using RAFT polymerization and the orientational cooperative effect. Macromolecules 41, 3823-3831 (2008).

$116 \mathrm{Yu}, \mathrm{H}$. , lyoda, T. \& Ikeda, T. Photoinduced alignment of nanocylinders by supramolecular cooperative motions. J. Am. Chem. Soc. 128, 11010-11011 (2006).

$117 \mathrm{Yu}, \mathrm{H} .$, Kobayashi, T. \& Hu, G.-H. Photocontrolled microphase separation in nematic liquid-crystalline diblock copolymer. Polymer 52, 1554-1561 (2011)

118 Morikawa, Y., Nagano, S., Watanabe, K., Kamata, K., lyoda, T. \& Seki, T. Optical alignment and patterning of nanoscale microdomains in a block copolymer thin film. Adv. Mater. 18, 883-886 (2006).

119 Morikawa, Y., Kondo, T., Nagano, S. \& Seki, T. Photoinduced 3D ordering and patterning of microphase-separated nanostructure in polystyrene-based block copolymer. Chem. Mater. 19, 1540-1542 (2007).

120 Seki, T. \& Nagano, S. Light-directed dynamic structure formation and alignment in photoresponsive thin films. Chem. Lett. 37, 484-489 (2008).

121 Zhao, Y. \& He, J. Azobenzene-containing block copolymers: the interplay of light and morphology enables new functions. Soft Matter 5, 2686 (2009).
122 Tong, X. \& Zhao, Y. in Liquid Crystals Beyond Displays (ed. Li, Q.) 285-301 (John Wiley \& Sons, Hoboken, USA, 2011).

$123 \mathrm{Yu}, \mathrm{H} .$, Kobayashi, T. \& Yang, H. Liquid-crystalline ordering helps block copolymer self-assembly. Adv. Mater. 23, 3337-3344 (2011).

$124 \mathrm{Yu}, \mathrm{H}$. Photoresponsive liquid crystalline block copolymers: from photonics to nanotechnology. Prog. Polym. Sci. 39, 781-815 (2014).

125 Watanabe, K., Watanabe, R., Aoki, D., Shoda, S., Komura, M., Kamata, K. \& lyoda, T. Alignment of self-organized nanocylinder array structure in amphiphilic liquid crystalline block copolymer. Trans. Mater. Res. Soc. Jpn 31, 237-240 (2006).

126 Nagano, S., Koizuka, Y., Murase, T., Sano, M., Shinohara, Y., Amemiya, Y. \& Seki, T. Synergy effect on morphology switching: real-time observation of photo-orientation of microphase separation in a block copolymer. Angew. Chem. Int. Ed. 51, 5884-5888 (2012).

127 Fukuhara, K., Fujii, Y., Nagashima, Y., Hara, M., Nagano, S. \& Seki, T. Liquid crystalline polymer and block copolymer domain alignment controlled by free-surface segregation. Angew. Chem. Int. Ed. 52, 5988-5991 (2013).

128 Fukuhara, K., Nagano, S., Hara, M. \& Seki, T. Free-surface molecular command systems for photoalignment of liquid crystalline materials. Nat. Commun. 5, 3321-3328 (2014).

129 Komiyama, H., lyoda, T. \& Kamata, K. Perpendicularly oriented cylinder nanostructure of liquid crystalline block copolymer film on Si substrate with various surface wettability. Chem. Lett. 41, 110-112 (2012).

(i) (2) (2) This work is licensed under a Creative Commons Attribution-NonCommercial-ShareAlike 3.0 Unported License. The images or other third party material in this article are included in the article's Creative Commons license, unless indicated otherwise in the credit line; if the material is not included under the Creative Commons license, users will need to obtain permission from the license holder to reproduce the material. To view a copy of this license, visit http://creativecommons.org/licenses/by-nc-sa/3.0/

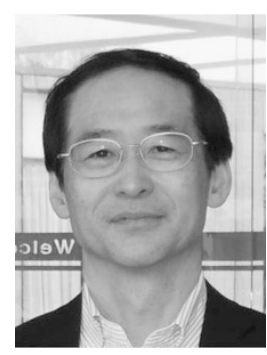

Takahiro Seki received his $\mathrm{PhD}$ from Tokyo Institute of Technology in 1986. He started an academic career at Tokyo Institute of Technology as a research associate. During 1986-1995, he held positions at the institutes of Agency of Industrial Science and Technology (AIST) at Tsukuba, the Research Institute of Polymers and Textiles (1986-1992) and the National Institute of Chemical and Materials Research (1993-1995). From 1995 to 2002, he was an Associated Professor in the Chemical Resources Laboratory of Tokyo Institute of Technology and appointed as a Professor of Graduate School of Engineering at Nagoya University in 2002. His research interests focus on photochromic materials, polymer thin films and liquid crystalline materials. He received the SPSJ Wiley Award in 2002, the Chemical Society of Japan Award for Creative Work in 2006 and the Award of the Society of Polymer Science, Japan in 2013. 